\title{
Atomic-scale characterization of occurring phenomena during hot nanometric cutting of single crystal $3 \mathrm{C}-\mathrm{SiC}$
}

\author{
Saeed Zare Chavoshi, Xichun Luo* \\ Centre for Precision Manufacturing, Department of Design, Manufacture and Engineering \\ Management, University of Strathclyde, Glasgow, G1 1XJ, UK \\ *xichun.luo@strath.ac.uk
}

\begin{abstract}
:
Nanometric cutting of single crystal 3C-SiC on the three principal crystal orientations at various cutting temperatures spanning from $300 \mathrm{~K}$ to $3000 \mathrm{~K}$ was investigated by the use of molecular dynamics (MD) simulation. The dominance of the (111) cleavage was observed for all the tested temperatures. An observation of particular interest was the shift to the (110) cleavage at cutting temperatures higher than $2000 \mathrm{~K}$. Another key finding was the increase of anisotropy in specific cutting energy from $\sim 30 \%$ at $300 \mathrm{~K}$ to $\sim 44 \%$ at $1400 \mathrm{~K}$, followed by a drop to $\sim 36 \%$ and $\sim 24 \%$ at $1700 \mathrm{~K}$ and $2000 \mathrm{~K}$, respectively. The obtained results also indicated that the specific cutting energies required for cutting surfaces of different orientations decrease by $33 \%-43 \%$ at $2000 \mathrm{~K}$ compared to what are required at $300 \mathrm{~K}$. Moreover, the position of stagnation region was observed to vary with changes in temperature and crystallographic orientation. Further analysis revealed that the subsurface deformation was maximum on the (111) surface whereas it was minimum on the (110) plane. This is attributable to the occurrence of cleavage and the location of the stagnation region. In addition, the amount of subsurface damage scaled linearly with the increase of cutting temperature. A vortex flow of atoms beneath the cutting tool was also observed, which is qualitatively analogous to the plastic flow of silicon. The simulations also predicted that the atom-
\end{abstract}


by-atom attrition wear and plastic deformation of the diamond cutting tool could be alleviated while cutting at high temperatures. Nevertheless, chemical wear i.e. dissolution-diffusion and adhesion wear is plausible to be accelerated at high temperatures.

Keywords: MD simulation; Hot nanometric cutting; 3C-SiC; Anisotropy

\section{Introduction}

Silicon carbide $(\mathrm{SiC})$ is a ceramic with outstanding mechanical and physical properties such as high strength, high thermal conductivity, high stability at high temperature, high resistance to shocks, low thermal expansion, low density, high refractive index, wide (tunable) bandgap and chemical inertness. This interesting material exhibits one-dimensional polymorphism characterized by different stacking sequences of the $\mathrm{Si}-\mathrm{C}$ bilayers. $3 \mathrm{C}-\mathrm{SiC}$, as a zinc blende structured $\mathrm{SiC}$, possesses the highest fracture toughness, hardness, electron mobility and electron saturation velocity amongst the $\mathrm{SiC}$ polytypes [1]. Thus, it has drawn substantial attention to be utilized in the fabrication of devices which require high performance in extreme environments. $3 \mathrm{C}-\mathrm{SiC}$ behaves as nearly an ideal brittle solid material at room temperature owing to its $s p^{3}$-bonded nature and short bond length. Accordingly, 3C-SiC exhibits poor machinability at room temperature. At high temperatures, yield strength and hardness of this nominally brittle material decreases and its fracture toughness improves. As a result, plastic deformation and machinability of $3 \mathrm{C}-\mathrm{SiC}$ enhances.

Available literature regarding molecular dynamics (MD) simulation of nanoscale cutting has mainly concentrated on elucidating material removal at room temperature $(300 \mathrm{~K})$ and only rudimentary studies have been performed on studying hot nanometric cutting. In a preliminary investigation performed in our research group, hot machining of single crystal 3C-SiC at $1200 \mathrm{~K}$ was compared with the cutting at $300 \mathrm{~K}$. It was found that hot machining results in lowering tangential cutting forces and thrust forces, yet shear plane angle remained unchanged [2]. In similar work, the authors 
[3-6] performed MD simulations to examine the characteristics of hot nanometric cutting of single crystal silicon at various temperatures. It was observed that the anisotropy increases with the increase of cutting temperature. Also, narrower shear zones were observed while cutting the (111) crystal plane or at higher cutting temperatures. Furthermore, smaller resultant force, friction coefficient at the tool/chip interface and chip temperature was witnessed on the (111) orientation, as opposed to the other orientations. There are also couple of MD studies on nanoindentation of silicon, copper, gold and diamond at elevated temperatures [7-10]. What is known from these high temperature nanoindentation studies is that Young's modulus, hardness and the extent of elastic recovery (spring back) decrease and softening increases with the increase of temperature. However, it must be noted that nanometric cutting unlike nanoindentation is dominated by shear stress and thus leads to more deviatoric stress conditions; hence providing a wider outlook of the material deformation.

It may thus be seen that there exists a relatively fair MD knowledge on hot nanometric cutting and nanoindentation of silicon and some other materials but hot nanometric cutting of $3 \mathrm{C}-\mathrm{SiC}$ is still in infant stage and needs therefor to be explored so as to fill the current pool of knowledge concerning high temperature deformation behaviour of 3C-SiC. In particular, there exists no experimental work up till now for nanometric cutting of 3C-SiC at elevated temperatures. It is evident that in order to be able to improve the hot nanometric cutting of 3C-SiC, it becomes necessary to have a clear and unequivocal understanding of the microscopic aspects of this process. To this end, simulation-based studies have to be performed. The obtained knowledge could be vital in implementing the hot nanometric cutting of 3C-SiC with the assistance of Laser processing. Accordingly, a series of MD simulations of nanometric cutting of $3 \mathrm{C}-\mathrm{SiC}$ on the (010), (110) and (111) crystallographic orientations at various temperatures $(300 \mathrm{~K}-3000 \mathrm{~K})$ were performed in this study using an analytical bond order potential (ABOP) [11] to obtain a clear and unequivocal understanding of the material removal behaviour i.e. anisotropic cutting behaviour, chip formation, plastic flow of 3C$\mathrm{SiC}$ workpiece and tool wear at different temperatures. 


\section{Simulation methodology}

MD simulations are implemented by using a public-domain computer code, known as "large-scale atomic/molecular massively parallel simulator" (LAMMPS) [12]. The three-dimensional nanometric cutting model of $3 \mathrm{C}-\mathrm{SiC}$ is demonstrated in Fig. 1. Basically, this model is a planestress condition representation of realistic machining process. Both $3 \mathrm{C}$-SiC workpiece and diamond cutting tool are built as deformable bodies. The region of atoms in the tool and the workpiece are divided into three different zones: boundary atom zone, thermostatic atom zone and Newtonian atom zone, in accord with the previously published studies [13-17]. The boundary atoms serve as rigid bases for the workpiece and tool and would maintain the symmetry of the lattice. The thermostatic atoms are allowed to follow Berendsen thermostatic dynamics to ascertain plausible outward heat conduction away from the machined zone which is carried away by chips and lubricants during actual machining. The Newtonian atoms whose behaviour is directed by the motion equations arising from their Hamiltonian are allowed to follow the Newtonian dynamics (LAMMPS NVE dynamics). In order to minimize the boundary effects, the length and height of the workpiece and cutting tool are selected adequately large.

The temperature of the atoms during the machining simulation can be computed using the following conversion between the kinetic energy and temperature:

$$
\frac{1}{2} \sum_{i} m_{i} v_{i}^{2}=\frac{3}{2} N k_{b} T
$$

where $N$ is the number of atoms, $v_{i}$ represents the velocity of $i$ th atom, $k_{b}$ is the Boltzmann constant $\left(1.3806503 \times 10^{-23} \mathrm{~J} / \mathrm{K}\right)$ and $T$ represents the atomistic temperature. However, the instantaneous fluctuations in kinetic energy (K.E.) of atoms would be very high so K.E. should be averaged (time and/or spatial) over few timesteps to convert into equivalent temperature. Since the movement of the cutting tool contributes to the kinetic energy, a modified kinetic energy should be applied so as to compute the average temperature of the cutting tool atoms. 


$$
\frac{1}{2} \sum_{i} m_{i}\left|v_{i}^{2}-v_{\text {tool }}^{2}\right|=\frac{3}{2} N k_{b} T
$$

where $\mathrm{v}_{\text {tool }}$ is the velocity of cutting tool. While calculating the temperature for tool, It is possible to use temp/com command, which this automatically subtracts the tool velocity.

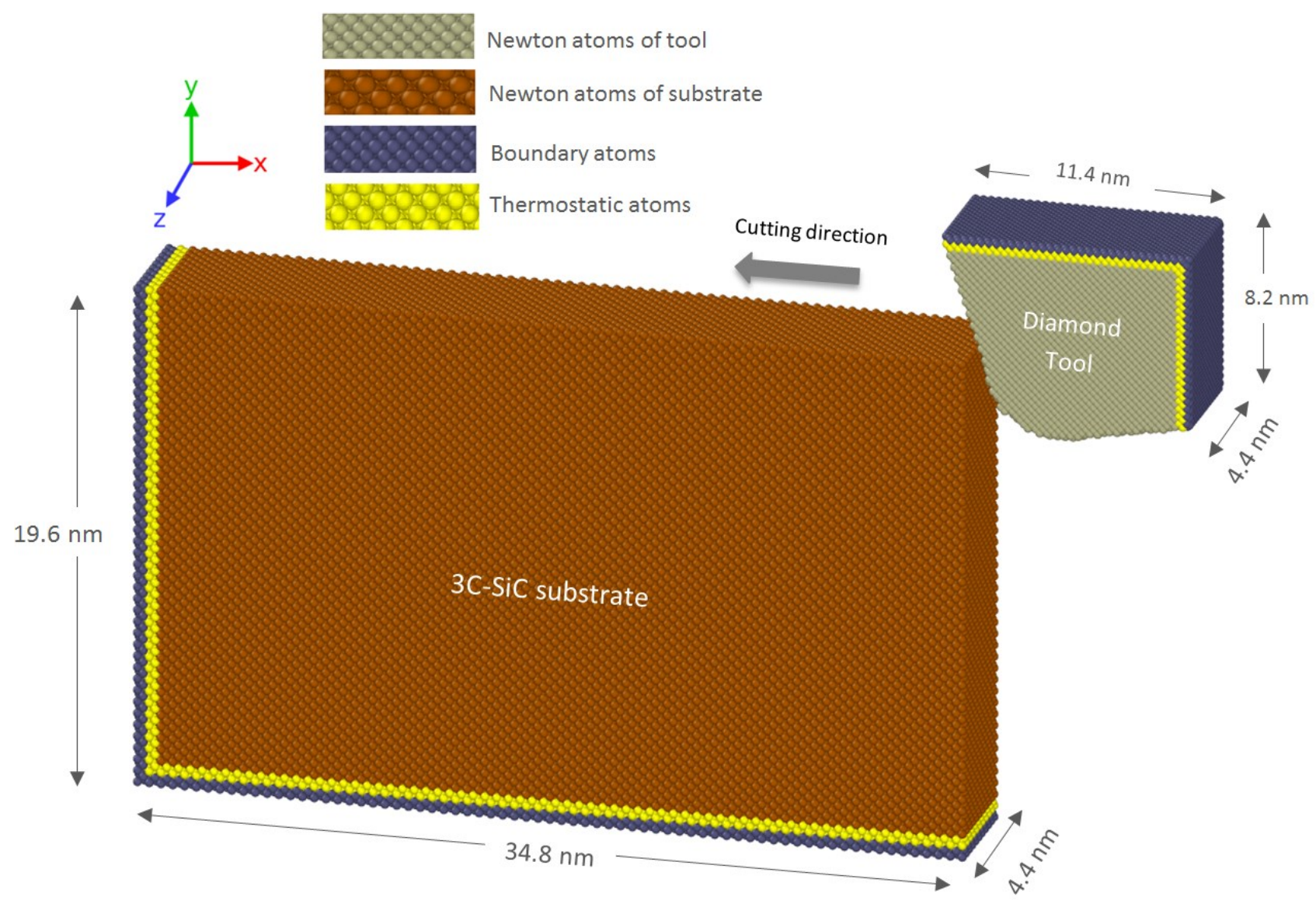

Fig. 1. Schematic of the MD simulation model

Interatomic potential function plays a pivotal role in the accuracy and reliability of the MD simulation results. Erhart and Albe [11] proposed a three-body potential function called ABOP formalism so as to dictate the interactions between the atoms within the $\mathrm{Si}-\mathrm{Si}, \mathrm{C}-\mathrm{C}$ and $\mathrm{Si}-\mathrm{C}$. Both bulk and dimer properties such as binding energy, $D_{0}$, the equilibrium bonding distance, $r$, and the wave number, $k$, of the ground-state oscillation can be precisely defined by this potential function. 
Hence, ABOP function was employed in this study to model hot nanometric cutting of single crystal 3C-SiC. In order to obtain accurate simulation results, the corresponding equilibrium lattice constants for the studied cutting temperatures i.e. $300 \mathrm{~K}, 900 \mathrm{~K}, 1200 \mathrm{~K}, 1400 \mathrm{~K}, 1700 \mathrm{~K}, 2000 \mathrm{~K}$ and $3000 \mathrm{~K}$ were calculated and accordingly were utilized to build the geometry of the workpiece. The cohesive energy corresponding to the equilibrium lattice constant of $3 \mathrm{C}$-SiC obtained from the simulation at various temperatures are summarized in Table 1. In all cases, the tool was equilibrated at $300 \mathrm{~K}$ before simulations; hence the lattice constant of $3.568 \AA$ calculated using the ABOP function at $300 \mathrm{~K}$ was used for the carbon atoms.

Table 1. Calculated equilibrium lattice constants and cohesive energies of single crystal 3C-SiC at different temperatures using ABOP function [11]

\begin{tabular}{|c|c|c|c|}
\hline Temperature $(\mathrm{K})$ & $\begin{array}{c}\text { Lattice } \\
\text { constant }(\AA)\end{array}$ & $\begin{array}{c}\text { Cohesive } \\
\text { energy }(\mathrm{eV})\end{array}$ & $\begin{array}{c}\text { Experimental } \\
\text { lattice constant } \\
(\AA)[18]\end{array}$ \\
\hline 300 & 4.3623 & -6.3376 & 4.3581 \\
\hline 900 & 4.3681 & -6.3342 & 4.3689 \\
\hline 1200 & 4.3712 & -6.3325 & 4.3754 \\
\hline 1400 & 4.3738 & -6.3297 & 4.3798 \\
\hline 1700 & 4.4291 & -6.1401 & - \\
\hline 2000 & 4.4409 & -6.1033 & - \\
\hline 3000 & 4.4838 & -5.9718 & - \\
\hline
\end{tabular}

To avoid the interaction between workpiece and tool atoms at the beginning of simulation, the cutting tool was placed at a distance of $10 \AA(1 \mathrm{~nm})$ away the workpiece surface. The model was then allowed to run for 30 ps to achieve the desired temperature. Table 2 lists the geometry details and process parameters used in this study. The nanometric cutting trials were simulated by advancing the tool atoms at every time step giving the tool a velocity of $50 \mathrm{~m} / \mathrm{s}$. This cutting speed was employed primarily due to limitation of computational power since implementation of parametric investigations at realistic cutting speeds $(\sim 1-2 \mathrm{~m} / \mathrm{s})$ would require very long computation times. Finally, “Open Visualization Tool” (OVITO) [19] was used to visualise and post-process the atomistic data. 
Table 2. Details of the MD simulation model and the cutting parameters used in the study

\begin{tabular}{|c|c|}
\hline Workpiece material & Single crystal 3C-SiC \\
\hline Workpiece dimensions & $34.8 \times 19.6 \times 4.4 \mathrm{~nm}^{3}$ \\
\hline Tool material & Single crystal diamond \\
\hline Cutting edge radius (tip radius) & $3.5 \mathrm{~nm}$ \\
\hline Uncut chip thickness (cutting depth in 2D) & $3 \mathrm{~nm}$ \\
\hline Cutting orientation and cutting direction & $\begin{array}{l}\text { Case } 1:(010)<100> \\
\text { Case } 2:(110)<00 \overline{1}> \\
\text { Case } 3:(111)<\overline{1} 10>\end{array}$ \\
\hline $\begin{array}{l}\text { Rake and clearance angle of the cutting } \\
\text { tool }\end{array}$ & $-25^{\circ}$ and $10^{\circ}$ \\
\hline Workpiece temperature & $\begin{array}{c}300 \mathrm{~K}, 900 \mathrm{~K}, 1200 \mathrm{~K}, 1400 \mathrm{~K}, 1700 \mathrm{~K}, 2000 \\
\mathrm{~K} \text { and } 3000 \mathrm{~K}\end{array}$ \\
\hline Cutting speed & $50 \mathrm{~m} / \mathrm{s}$ \\
\hline Time step & $1 \mathrm{fs}$ \\
\hline Potential energy function & ABOP [11] \\
\hline
\end{tabular}

\section{Results and discussion}

\subsection{Cutting forces and specific cutting energy}

From the MD simulation standpoint, the cutting forces can be calculated by summing up the total forces exerted by the carbon atoms of the cutting tool to the $3 \mathrm{C}$-SiC workpiece. The force components along the $x, y$ and $z$ directions describe tangential, thrust and axial forces, respectively. Surface form error is chiefly affected by thrust force since this component of force has tendency to separate the tool away from the workpiece. The tangential force brings about displacements in the direction of cut chip thickness and its variation therefore associates to chatter. Hence, the cutting 
behaviour changes dynamically i.e. wear, fracture, elastic-plastic transition, displacement of the material, heat generation, wear of the tool, dislocation slip etc. leading to change of the force as per along the length of cut. The magnitude of the average tangential cutting forces, thrust forces, resultant forces and specific cutting energy for all the studied temperatures and crystal planes has been summarized in Table 1A in Appendix A. The average values of the forces were calculated only after the tool penetrated in the workpiece by 15 to $25 \mathrm{~nm}$, as shown in Fig. 2. At the beginning stage of cutting, both the tangential and thrust forces are zero. As the diamond cutting tool starts moving towards the single crystal 3C-SiC workpiece, the negative forces are observed, as illustrated in Fig. 2, signifying the effects of long-range attraction forces. Atoms attract each other when the instantaneous distance between two atoms is longer than the equilibrium distance between them. As the cutting tool advances more, cutting forces on the tool atoms alter to repulsive and climb proportionally, in a sense of average, with the cutting length. From Table 1A in Appendix A, it is conspicuous that the values of tangential, thrust and resultant forces decrease with the rise of workpiece temperature for various crystal surfaces. With the increase of temperature, the amplitude of atomic vibration within the workpiece increases. It is regarded as an increase in the number of phonons. This phenomenon results in generating atomic displacements. The atomic displacements within the workpiece causes a rise in the interatomic distances and a decrease in the restoring forces owing to thermal expansion, resulting in lowering the energy needed to break the atomic bonds. As a consequence, thermal softening occurs which reduces the cutting force required to deform the $3 \mathrm{C}$ SiC workpiece at high temperatures. 


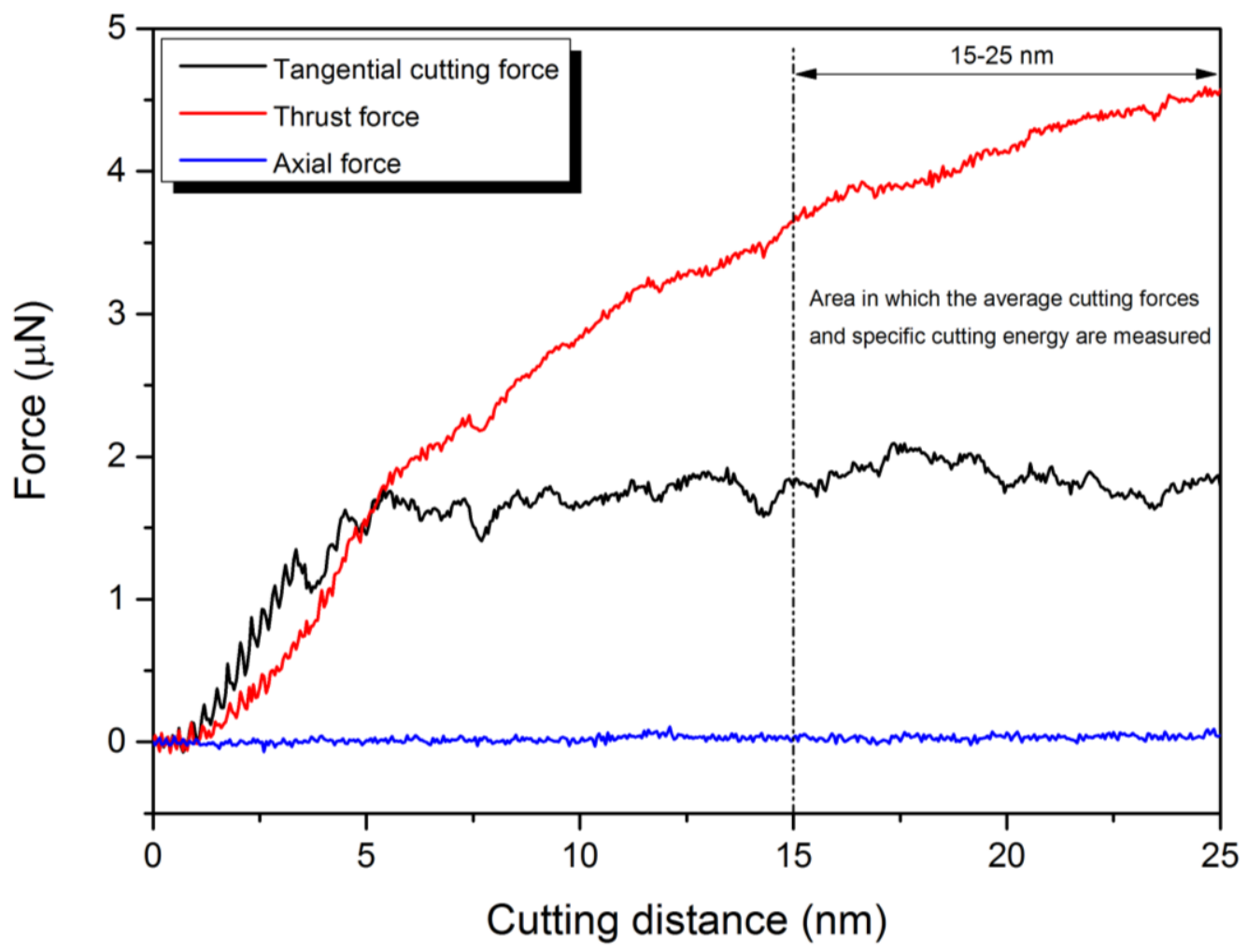

Fig. 2. An MD output of the force plot showing the region where the average cutting forces and specific cutting energy were measured

The machinability and cutting resistance of materials can be indicated by the "specific cutting energy", which is the energy required to remove a unit amount of material. The specific cutting energies can be calculated by dividing the resultant force by the chip area or volume, and it is expressed in $N / \mathrm{m}^{2}$ or $\mathrm{J} / \mathrm{m}^{3}$ [6]. In general, the lower the specific cutting energy, the higher the efficiency of the cutting process is. Fig. 3 shows that large specific cutting energy values correspond to low workpiece temperatures since the $3 \mathrm{C}-\mathrm{SiC}$ workpiece at a low temperature is more difficult to be deformed. It can be also observed that the (111) crystal plane requires least specific cutting energy while the highest magnitudes emerge on the (110) orientation. Hence, it can be deduced that the $(111)<\overline{1} 10>$ crystal setup is the easy orientation setup for cutting $3 \mathrm{C}$-SiC. This particular behaviour of $3 \mathrm{C}-\mathrm{SiC}$ is similar to another important semiconductor, silicon [6]. Table 3 highlights the percentage reduction in the specific cutting energy during hot nanometric cutting with respect to cutting at $300 \mathrm{~K}$ on varoious crystal surfaces. It is observed that, for instance, the sepecific cutting 
energy reduces up to $33 \%$ while cutting the (111) crystal plane at $2000 \mathrm{~K}$. Also, it can be inferred that at high temperatures, i.e. $2000 \mathrm{~K}$ and $3000 \mathrm{~K}$, the minimum reduction in specific cutting energy appears on the (111) plane whereas at lower temperatures the maximum reduction emergies on this plane. Fig. 4 illustrates the variation of crystallography-induced anisotropy in the specific cutting energy as a function of workpiece temperature. It can be seen that the anisotropy increases from $\sim 30 \%$ at $300 \mathrm{~K}$ to $\sim 44 \%$ at $1400 \mathrm{~K}$ and afterwards it decreases to $\sim 36 \%, \sim 24 \%$ and $\sim 22 \%$ at 1700 $\mathrm{K}, 2000 \mathrm{~K}$ and $3000 \mathrm{~K}$, respectively. The trend is on the contrary to the anistropy in specific cutting energy of siliocn, where it constantly increased with the increase of cutting temperature [6].

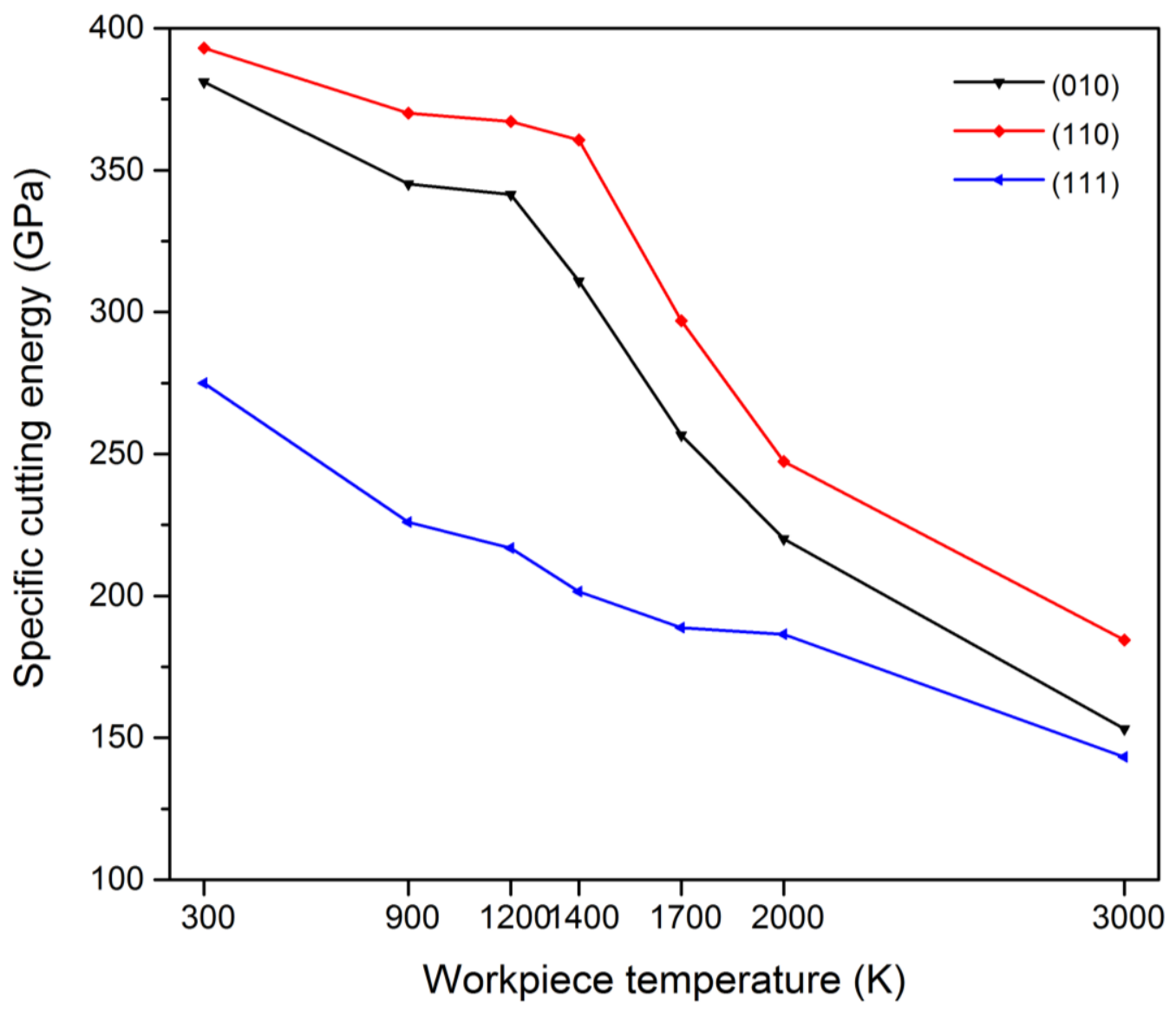

Fig. 3. Specific cutting energy as a function of temperature and crystal orientation 
Table 3. Percentage reduction in specific cutting energy of $3 \mathrm{C}-\mathrm{SiC}$ at high temperatures relative to room temperature

\begin{tabular}{|c|c|c|c|}
\hline $\begin{array}{c}\text { Crystal } \\
\text { orientation }\end{array}$ & $\begin{array}{c}\text { \% reduction in } \\
\text { cutting energy at } \\
1400 \mathrm{~K} \\
\text { compared to } 300 \\
\mathrm{~K}\end{array}$ & $\begin{array}{c}\text { \% reduction in } \\
\text { cutting energy at } \\
2000 \mathrm{~K} \\
\text { compared to } 300 \\
\mathrm{~K}\end{array}$ & $\begin{array}{c}\text { \% reduction in } \\
\text { cutting energy at } \\
3000 \mathrm{~K}\end{array}$ \\
$\begin{array}{c}\text { compared to } 300 \\
\mathrm{~K}\end{array}$ \\
\hline$(010)$ & Up to $19 \%$ & Up to $43 \%$ & Up to $60 \%$ \\
\hline$(110)$ & Up to $9 \%$ & Up to $38 \%$ & Up to $54 \%$ \\
\hline$(111)$ & Up to $27 \%$ & Up to $33 \%$ & Up to $48 \%$ \\
\hline
\end{tabular}

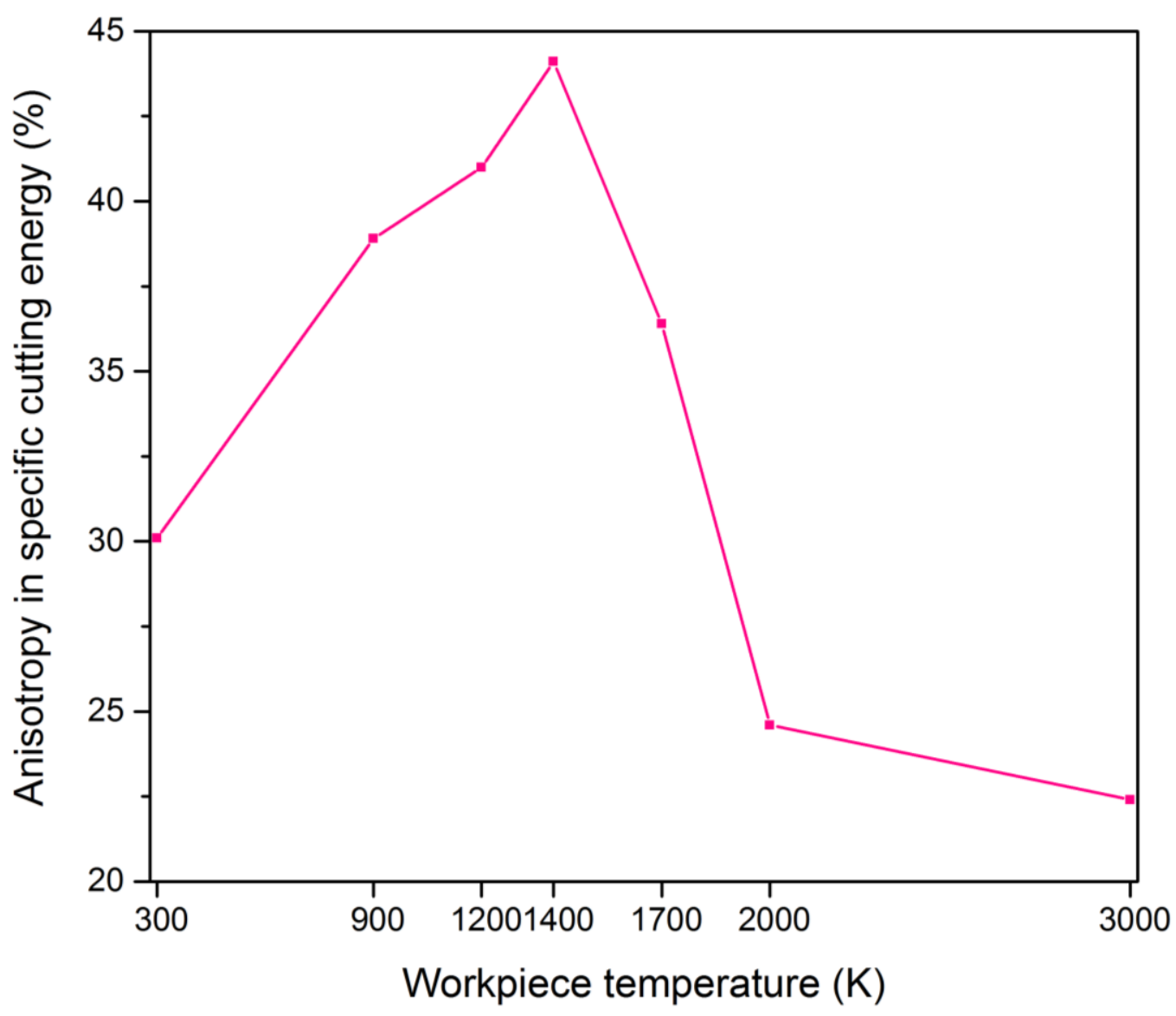

Fig. 4. Variation of anisotropy in specific cutting energy as a function of temperature 


\subsection{Chip formation and characteristics}

During nanometric cutting, the cutting edge of the tool penetrates into the workpiece atoms and separates the atoms near the tool tip. The separated atoms slide off along the rake face of the cutting tool at a constant velocity in a stationary flow, leading to the formation of cutting chip. A stagnant region ahead of the cutting tool divides the plastic flow into upward and downward directions, as shown in Fig. 5. In other words, above the stagnation region, atoms flow up along the rake face and consequently form the chip. Underneath the stagnation region, atoms compress downward into the workpiece leading to the formation of the freshly machined surface. The location of the stagnation region can be determined through calculation of the average displacement of workpiece atoms in $y$ direction in various layers. Fig. 6 represents displacements of different layers in the workpiece when nanometric cutting of $3 \mathrm{C}-\mathrm{SiC}$ is performed on the (110) crystal surface at $1400 \mathrm{~K}$. Slope alternation of the displacement line from positive to negative is an indication of the stagnation zone. To be more precise, in the stagnation region the displacement line has an almost zero slope. Table 4 summarizes the position of stagnation region and stagnation angles for the studied cases.

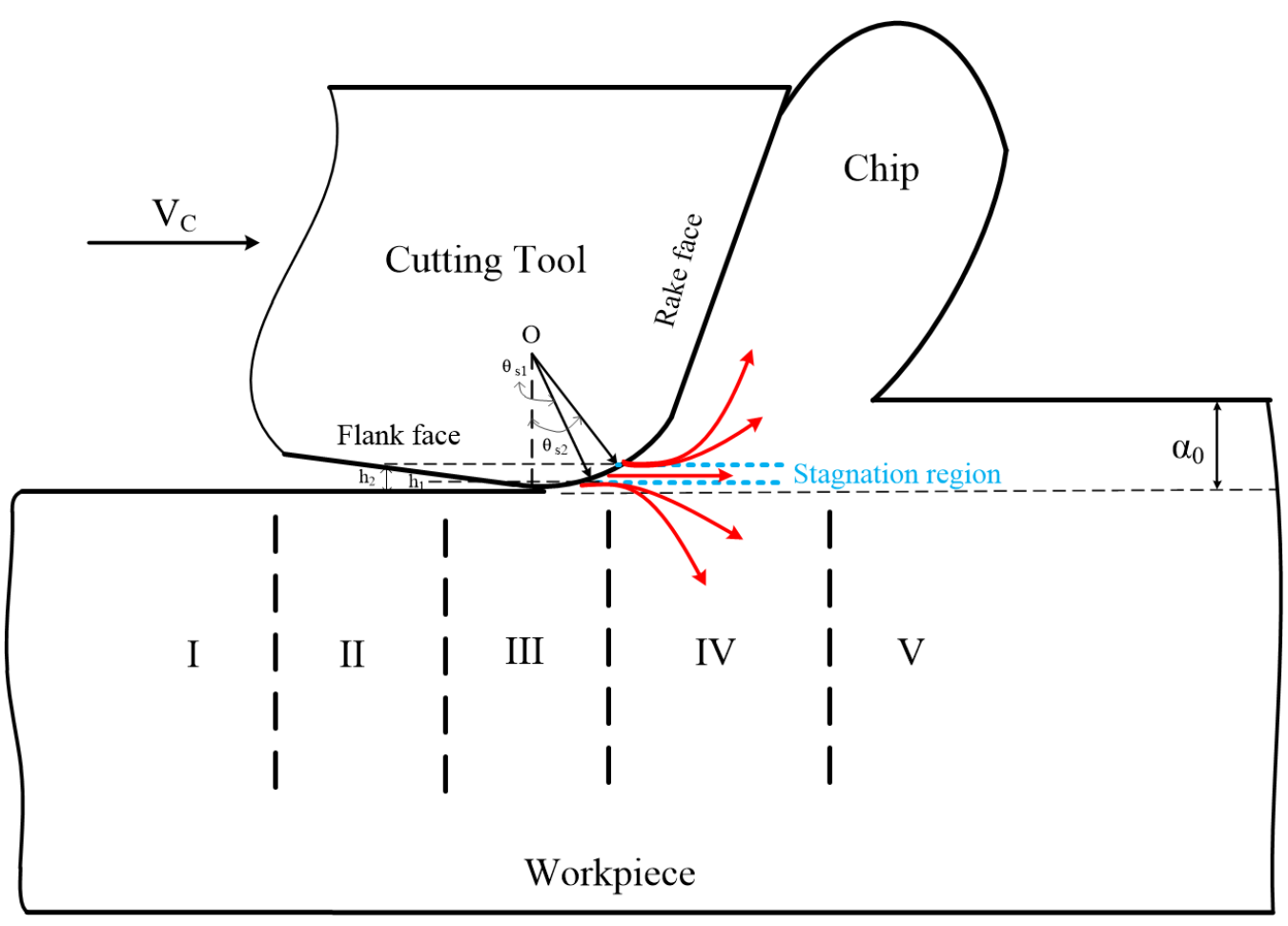


Fig. 5. Schematic view of chip formation demonstrating the stagnation region and five distinct zones within the workpiece: I- Cut zone, II- Below the flank face, III- Between the flank face and tool tip IV-Ahead and underneath the tool tip, V- Uncut zone. $\theta_{s 1,2}$ and $h_{1,2}$ show the limiting bounds of the stagnation region.

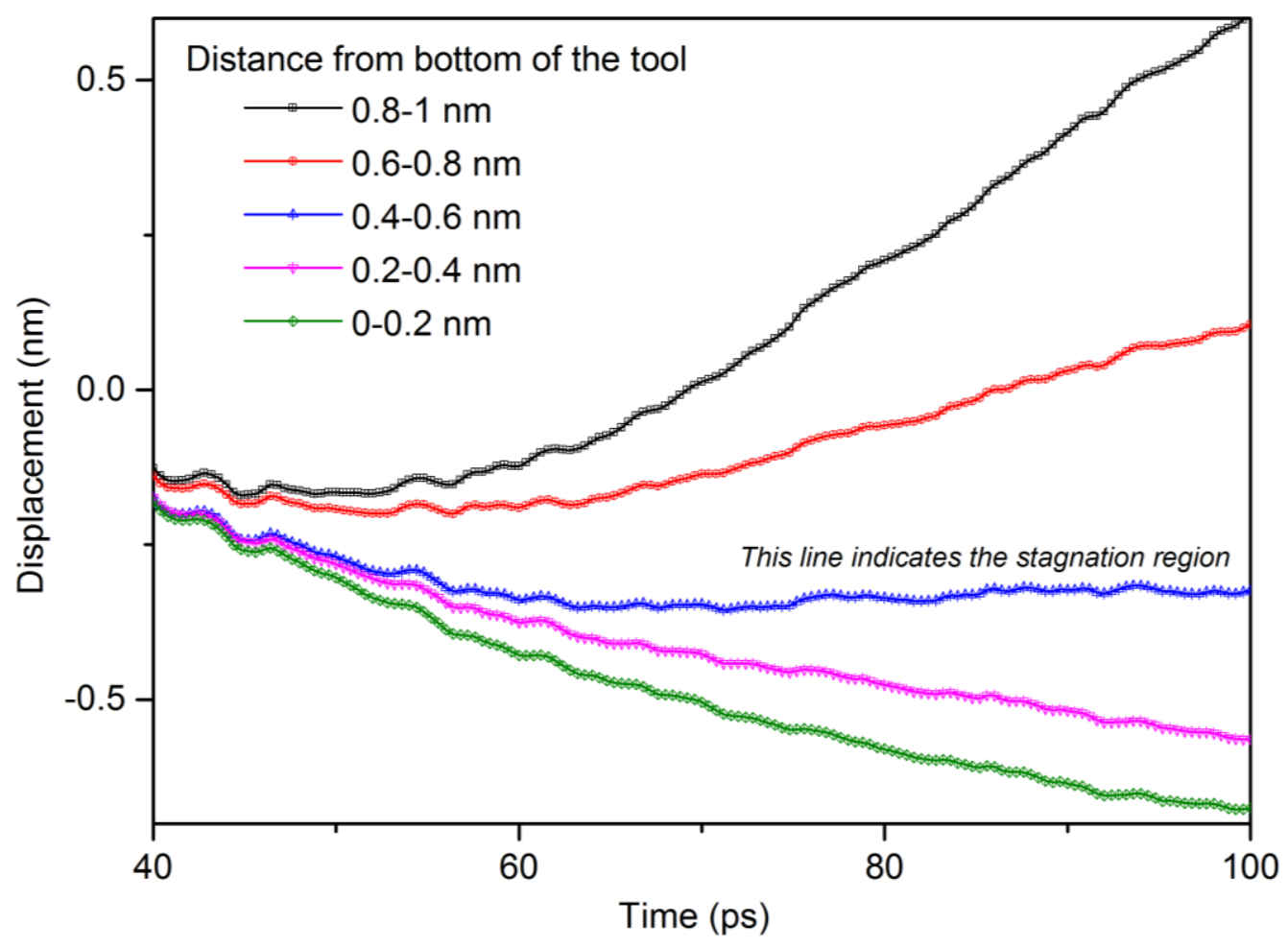

Fig. 6. Displacement of various layers in $y$ direction while cutting 3C-SiC on the (110) crystal plane at $1400 \mathrm{~K}$

It can be deduced from Table 4 that while cutting the (111) crystal plane at different temperatures, the stagnation region is located at an upper position than other planes, which indicates ploughing caused by compression is more pronounced on the (111) surface and therefore a thicker deformed region is expected to be generated, which may result in higher elastic recovery. The converse scenario occurs for the (110) orientation, where the stagnation region is located at a lower position than those of other crystal orientations. It can be also inferred that at high temperatures the stagnation region is located lower than that at room temperature, attributable to the thermal softening and enhanced plasticity of 3C-SiC workpiece. Interestingly, it is found that the $3 \mathrm{C}-\mathrm{SiC}$ exhibits the same general trend observed for the position of stagnation region during nanometric cutting of silicon at elevated temperatures [3]. An attempt was also made to compare the 
magnitudes of stagnation angle and friction angle. The stagnation angle $\left(\theta_{s}\right)$ illustrated in Fig. 5 was calculated from:

$$
\theta_{s 1,2}=\cos ^{-1}\left(1-\frac{h_{1,2}}{r}\right)
$$

where $h_{1,2}$ and $r$ are the limit bounds of stagnation region and tool tip radius, respectively. While using a rounded edge tool, the friction angle $(\beta)$ can be also calculated from:

$$
\begin{array}{r}
\beta=\alpha_{e f}+\tan ^{-1}\left(\frac{F_{c}}{F_{t}}\right) \\
\alpha_{e f}=\sin ^{-1}\left(1-\frac{d}{r}\right)
\end{array}
$$

where $\alpha_{e f}$ stands for the effective rake angle, $F_{c}$ and $F_{t}$, respectively, represent the tangential and thrust forces, and $d$ is the uncut chip thickness. It is observed from Table 4 that up to $1400 \mathrm{~K}$, the values of stagnation and friction angle are closely correlated for the (110) crystallographic orientation. Nonetheless, there exists a discrepancy between two angles while cutting the (010) and (111) planes or at high temperatures i.e. $2000 \mathrm{~K}$ and $3000 \mathrm{~K}$, particularly the difference is more

\begin{tabular}{|c|c|c|c|c|}
\hline $\begin{array}{l}\text { Workpiece } \\
\text { Temperature } \\
\text { (K) }\end{array}$ & $\begin{array}{l}\text { Crystal } \\
\text { orientation }\end{array}$ & $\begin{array}{l}\text { Position of stagnation region } \\
\text { from bottom of the tool }\left(h_{1,2}\right) \\
(\mathrm{nm})\end{array}$ & $\begin{array}{l}\text { Stagnation angles } \\
\left(\theta_{s 1,2}\right)(\text { degree })\end{array}$ & $\begin{array}{l}\text { Friction angle } \\
(\beta) \text { (degree) }\end{array}$ \\
\hline \multirow{3}{*}{300} & $(010)$ & $0.9-1.1$ & $42-46.7$ & 33 \\
\hline & (110) & $0.6-0.8$ & $34-39.9$ & 34.3 \\
\hline & $(111)$ & $1.1-1.3$ & $46.7-55.5$ & 44 \\
\hline
\end{tabular}
marked for the high cutting temperatures.

Table 4. Stagnation region, stagnation angle and friction angle while cutting 3C-SiC 


\begin{tabular}{|c|c|c|c|c|}
\hline \multirow{3}{*}{900} & $(010)$ & $0.8-1$ & $39.9-44.4$ & 32.4 \\
\hline & $(110)$ & $0.5-0.7$ & $31-36.9$ & 32.2 \\
\hline & $(111)$ & $1-1.2$ & $44.4-48.9$ & 44.9 \\
\hline \multirow{3}{*}{1200} & $(010)$ & $0.7-0.9$ & $36.9-42$ & 32.7 \\
\hline & $(110)$ & $0.5-0.7$ & $31-36.9$ & 31.1 \\
\hline & (111) & $0.7-0.9$ & $36.9-42$ & 45.7 \\
\hline \multirow{3}{*}{1400} & $(010)$ & $0.6-0.8$ & $34-39.9$ & 34.1 \\
\hline & (110) & $0.4-0.6$ & $27.7-34$ & 32.2 \\
\hline & (111) & $0.7-0.9$ & $36.9-42$ & 47.4 \\
\hline \multirow{3}{*}{1700} & $(010)$ & $0.6-0.8$ & $34-39.9$ & 36.5 \\
\hline & (110) & $0.3-0.5$ & $23.9-31$ & 36.2 \\
\hline & (111) & $0.7-0.9$ & $36.9-42$ & 46.8 \\
\hline \multirow{3}{*}{2000} & $(010)$ & $0.5-0.7$ & $31-36.9$ & 37.8 \\
\hline & (110) & $0.3-0.5$ & $23.9-31$ & 39 \\
\hline & (111) & $0.6-0.8$ & $34-39.9$ & 49 \\
\hline \multirow{3}{*}{3000} & $(010)$ & $0.2-0.4$ & $19.5-27.7$ & 40.1 \\
\hline & (110) & $0.1-0.3$ & $13.7-23.9$ & 41.3 \\
\hline & (111) & $0.5-0.7$ & $31-36.9$ & 50.3 \\
\hline
\end{tabular}


It has been reported that during nanometric cutting of $3 \mathrm{C}-\mathrm{SiC}$ on the (111) plane at room temperature, cleavage occurs ahead of the cutting tool [20]. Indeed, it is generalized that cleavage is a dominant mechanism on the (111) crystal orientation, and the (111) plane is the most commonly observed fracture plane of 3C-SiC. In order to realize whether cleavage takes place in nanometric cutting on the various crystallographic orientations at elevated temperatures, the chip formation process was carefully examined and the local environment of atoms up to the second neighbour shell was monitored. Fig 7 illustrates the chip formation at three stages together with the evolution of cutting forces while cutting the (111) crystal surface at $1400 \mathrm{~K}$. Crystallites of $3 \mathrm{C}-\mathrm{SiC}$ in the cutting chip can be observed, suggesting the occurrence of cleavage at high temperature of $1400 \mathrm{~K}$. In fact, the cleavage was observed to occur for all the simulated temperatures, $300 \mathrm{~K}-3000 \mathrm{~K}$, while cutting the (111) surface, which have not been shown here for the purpose of brevity. However, at high temperature of $3000 \mathrm{~K}$, smaller amount of crystallites were observed in the chip in comparison to those of lower temperatures, plausibly due to improved plasticity at this temperature. The substantial dominance of the (111) cleavage plane can be attributed to the lower cleavage energy and fracture surface energy of this plane as opposed to the other crystal orientations. This specific characteristic of 3C-SiC is comparable with that of diamond [21]. As evident from Fig. 7 (b), cutting forces experience an abrupt drop at the points where cleavage occurs, resultant from flaking off the crystallite of $3 \mathrm{C}-\mathrm{SiC}$ without undergoing amorphization. Thus, as the cutting tool does not carry out any work on a portion of atoms, the cutting force drops [20]. 


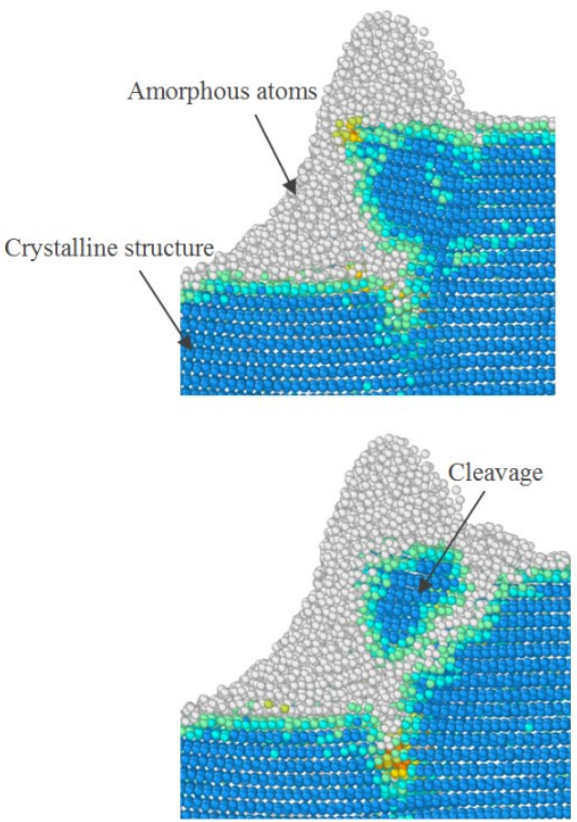

1
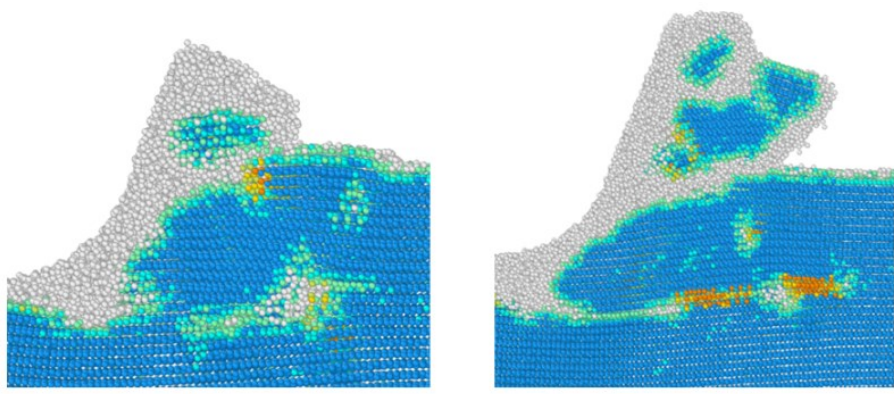

Before

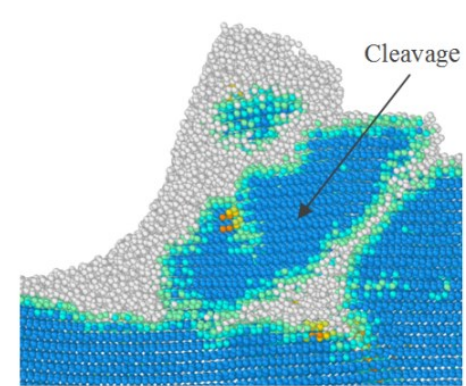

2

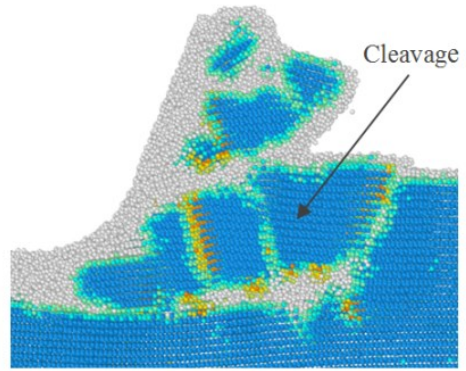

3

(a)

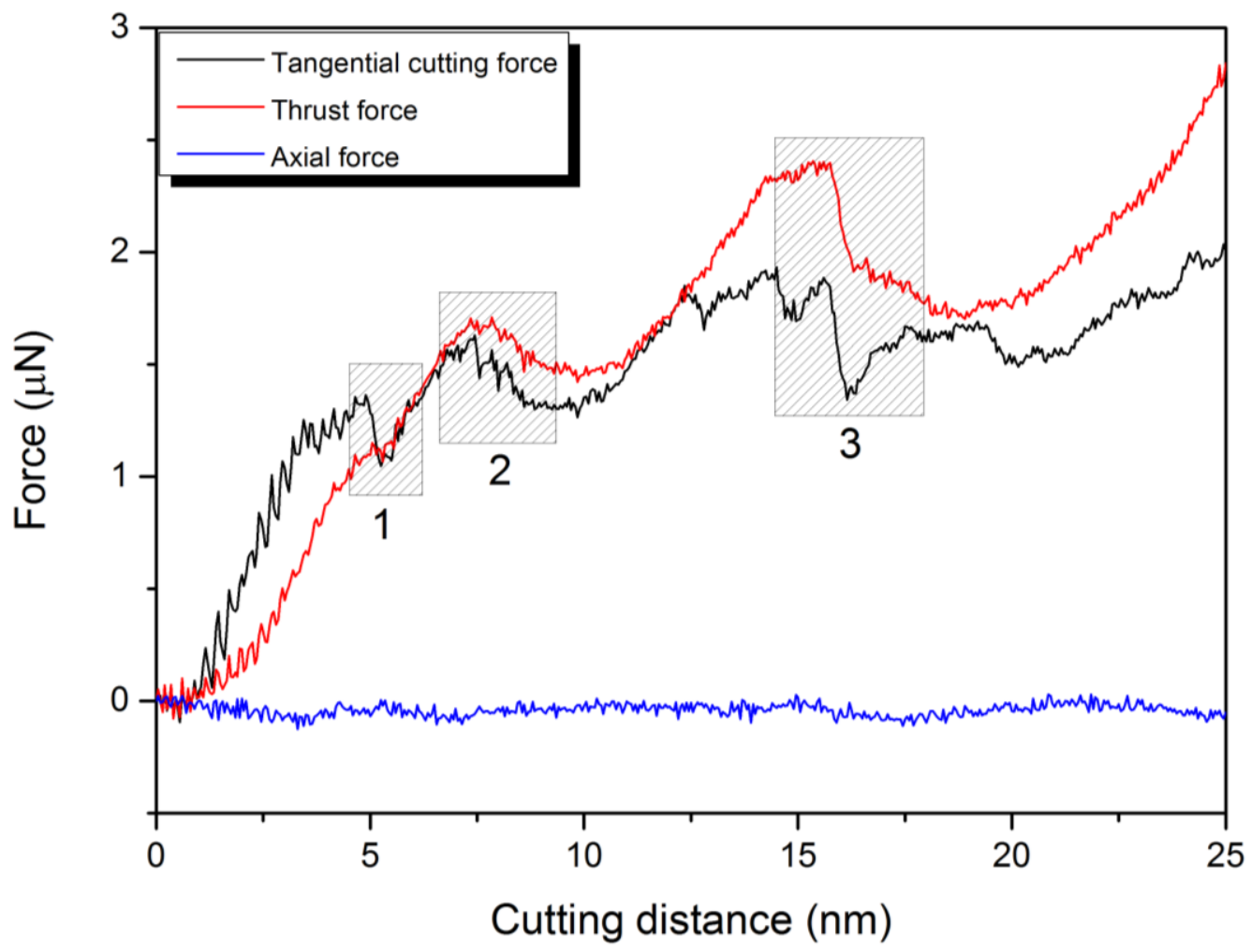

(b)

Fig. 7. a) Snapshots from the MD simulation while cutting the (111) crystal plane at $1400 \mathrm{~K}$ demonstrating the occurrence of cleavage at three stages and b) the corresponding drops of cutting forces 
While cleavage is anticipated to be dominant on the (111) orientation, a shift to the (110) cleavage at the cutting temperatures higher than $2000 \mathrm{~K}$ was seen during nanometric cutting processes , as shown in Fig 8. It is of note that the event of cleavage was observed to occur alongside with the formation and annihilation of stacking fault-couple, locks and cross-junctions between pairs of counter stacking faults [22]. Such (110) cleavage event is in accord with the earlier observations on the diamond under blunt indentations at high temperature [23], where shear stresses and plastic flow are thought to dictate the failure and the stress fields are inhomogeneous. It should be mentioned here that the diamond shares the same cubic lattice structure in its $s p^{3}$ bonded state with $3 \mathrm{C}-\mathrm{SiC}$. Hence, similarities in the material behaviour under contact loading problems could be expected. Note that very small amount of remnants of cleavage was observed for some other cases, i.e. on the (010) and (110) at $300 \mathrm{~K}$.

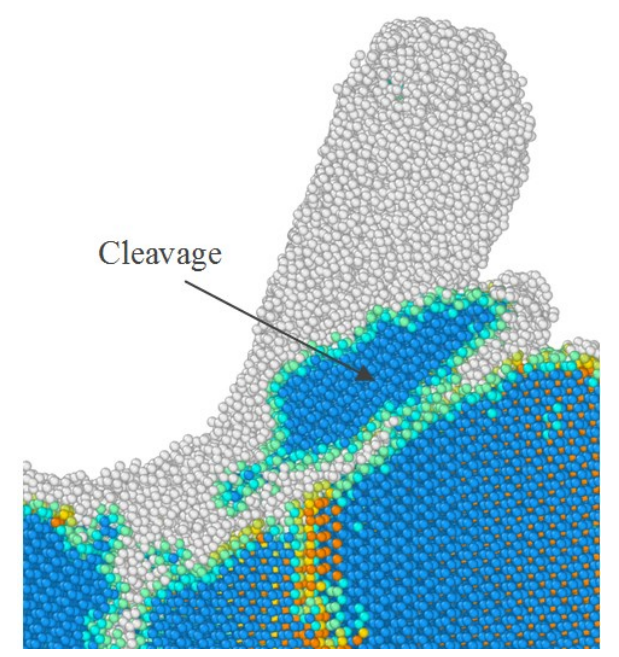

Fig. 8. Snapshot from the MD simulation showing the event of cleavage while cutting the (110) crystal plane at $2000 \mathrm{~K}$

From Fig. 9, it can be observed that the number of atoms in the cutting chip increases with the increase of workpiece temperature except for the (111) crystal plane at $3000 \mathrm{~K}$. Moreover, the 
highest number of atoms in the chip appears on the (111) plane; however it drops at $3000 \mathrm{~K}$. As mentioned earlier, large volume of cleavage is occurred while cutting the (111) crystal plane thus it is sensible to observe higher number of atoms in the chip while cutting the (111) plane. Furthermore, as seen in Fig. 10, the depth of subsurface deformation layer becomes deeper when the temperature of workpiece rises. As noted earlier, increase of the workpiece temperature will weaken interatomic bonding which triggers more crystal deformation within subsurface atoms. Thus, the layer depth of deformation becomes larger. This specific behaviour seemingly appears to be common in both single crystal 3C-SiC and silicon [4]. Another light can be brought by Fig. 10 is that the depth of subsurface deformation layer is the highest on the (111) plane whereas it is the lowest on the (110) orientation. The occurrence of cleavage and pronounced ploughing due to compression as a result of the upper position of stagnation region on the (111) plane could have the key role in this observation.

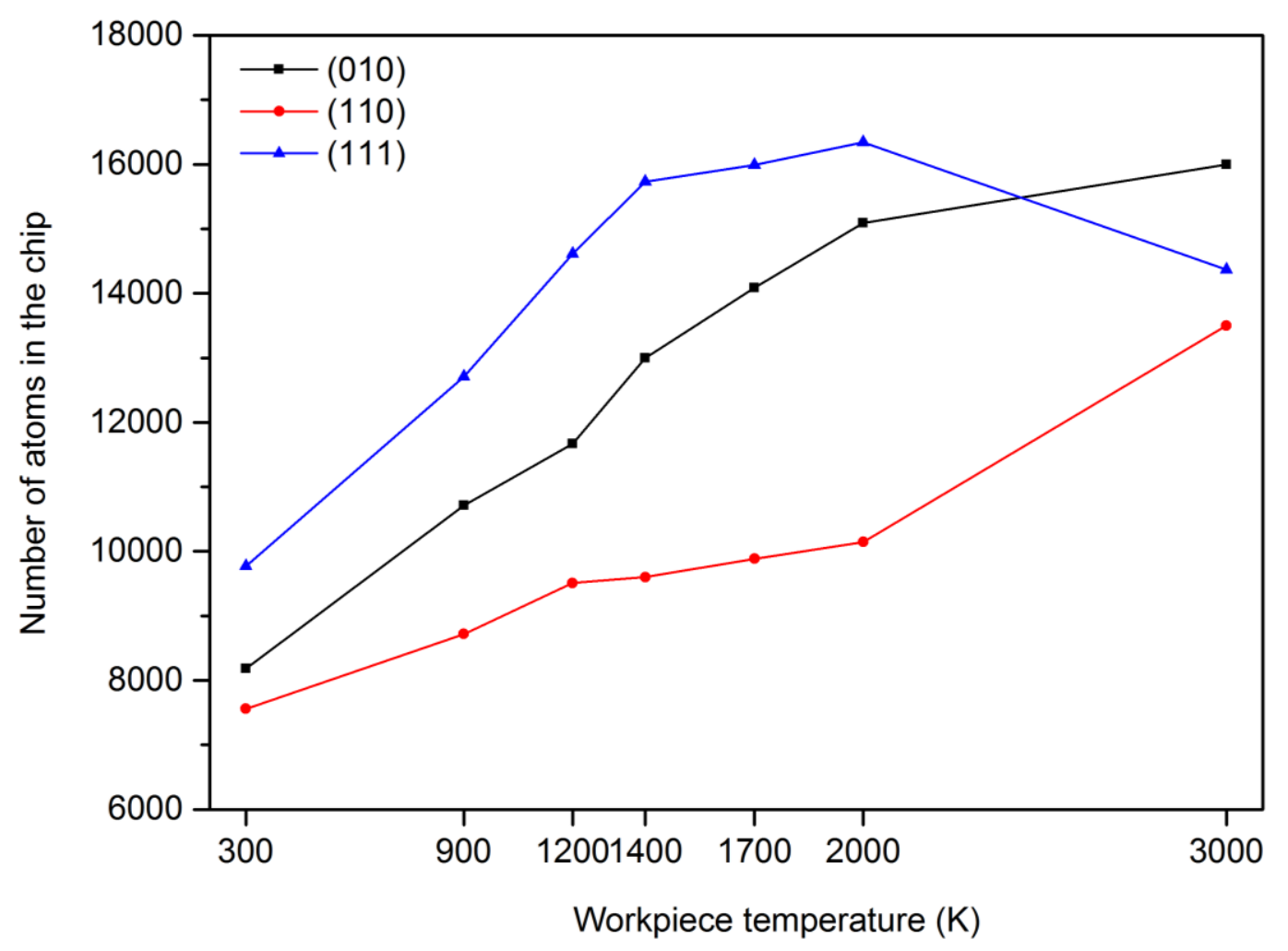

Fig. 9. Number of atoms in the cutting chip as a function of cutting temperature and crystal orientation 


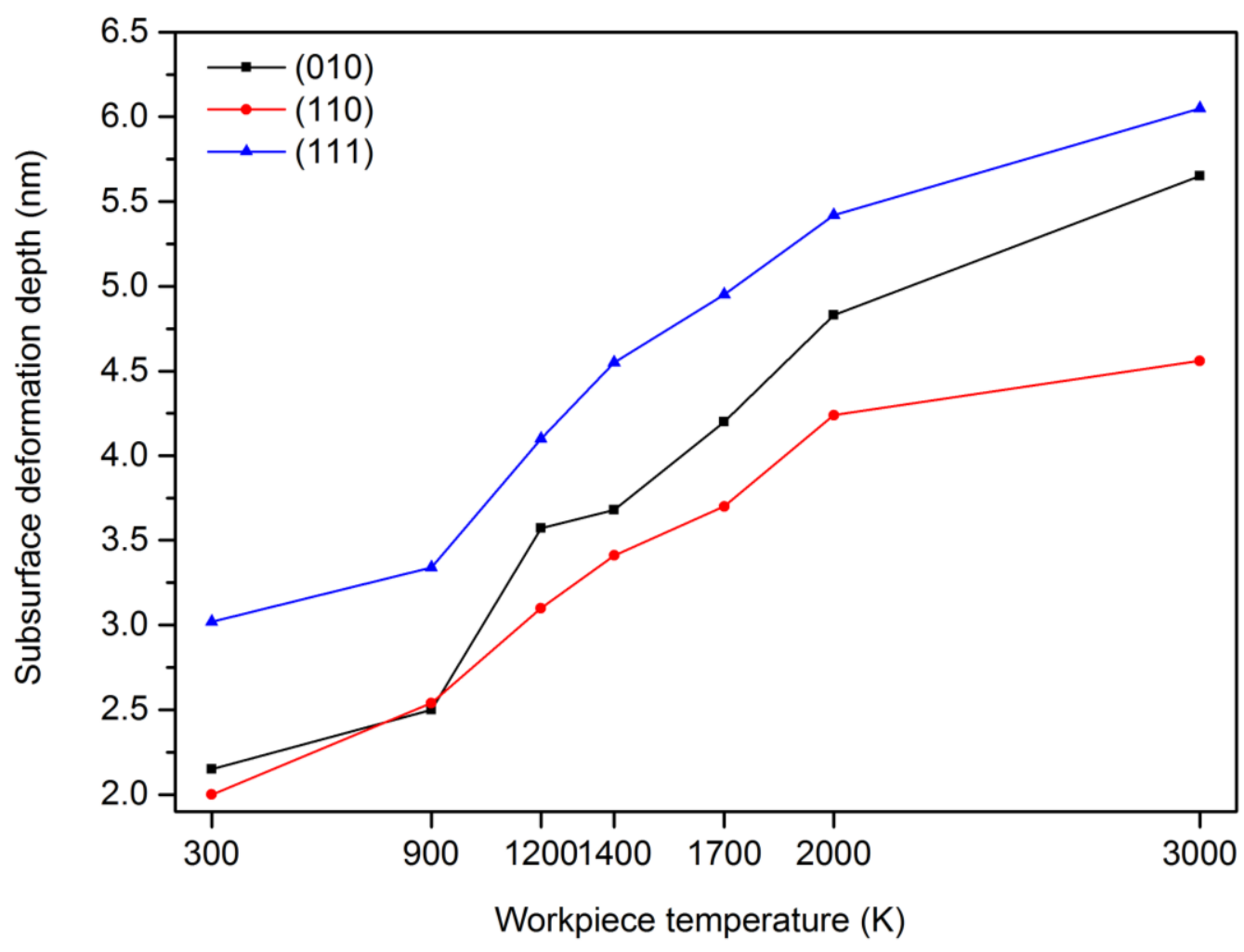

Fig. 10. Subsurface deformation layer depth as a function of cutting temperature and crystal orientation

Fig. 11 shows the variation of resultant force exerted by the tool rake face on the chip, and friction coefficient at the tool rake face/chip interface while cutting $3 \mathrm{C}-\mathrm{SiC}$ on different crystallographic planes at various temperatures. Clearly, the values of resultant force exerted by the tool rake face on the chip are found to be smallest while cutting $3 \mathrm{C}-\mathrm{SiC}$ on the (111) crystal plane whereas they are largest on the (110) orientation, which is consistent with the previous observations in this study. The friction coefficient at the tool rake face/chip interface varies from 0.42 to 0.9 on different crystal planes and temperatures. It may be noted that the friction coefficient is minimum on the (111) orientation. A remarkable observation is that the friction coefficient at the tool rake face/chip interface on the (110) and (010) orientations increases in the temperature range of $300 \mathrm{~K}$ to $1200 \mathrm{~K}$ and $300 \mathrm{~K}$ to $900 \mathrm{~K}$, respectively, as opposed to the (111) crystal plane, where the friction coefficient constantly decreases with the increase of workpiece temperature. 


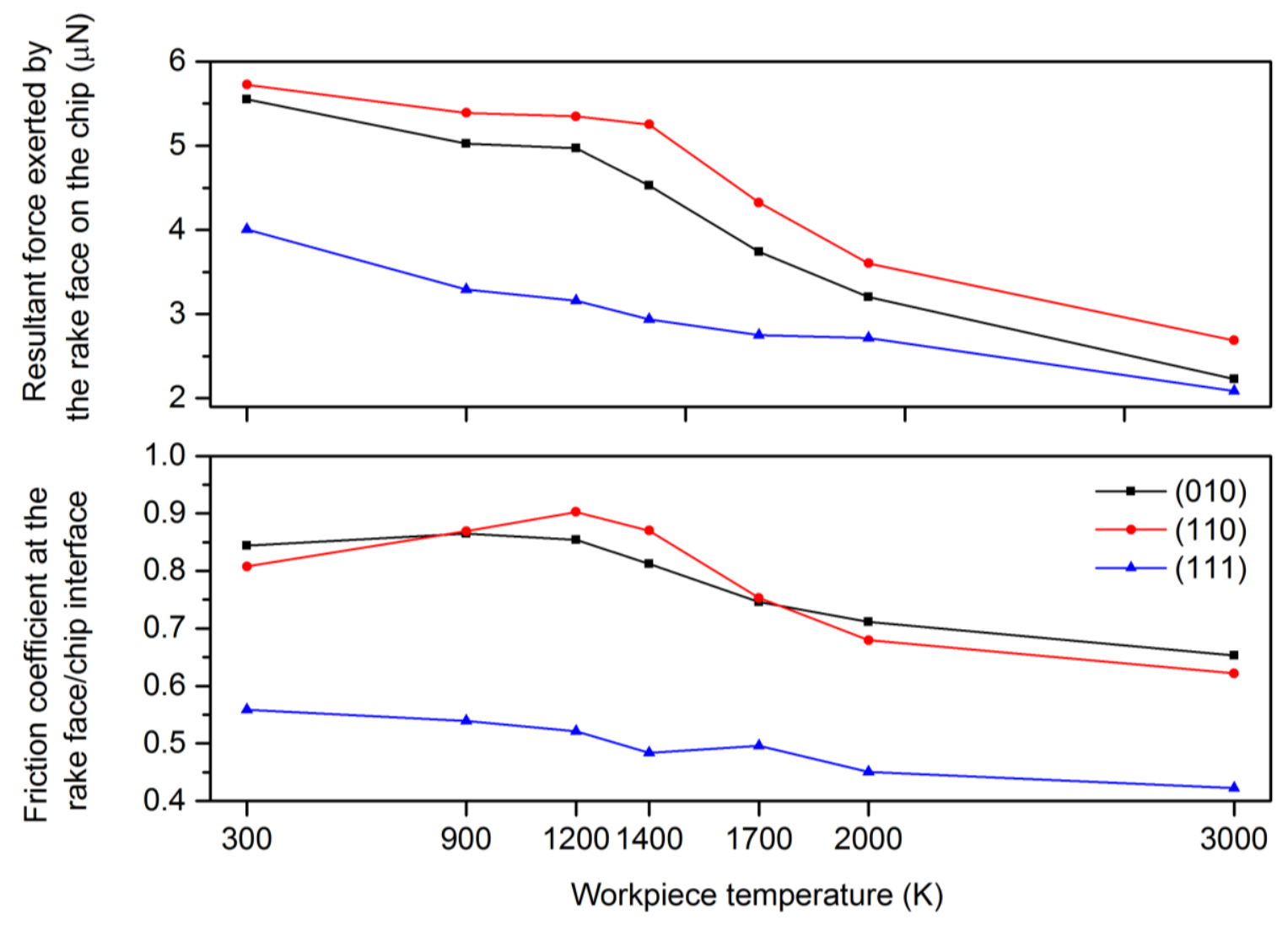

Fig. 11. Variations of the resultant force exerted by the tool rake face on the chip, and friction coefficient at the tool rake face/chip interface while cutting $3 \mathrm{C}$-SiC on different crystallographic planes at various temperatures

The theory of heat release in the primary, secondary and tertiary deformation zones is well documented. During nanometric cutting, heat is generated owing to the energy release as a result of the breaking and reformation of bonds in the primary deformation zone and owing to the friction at the interface of the cutting tool and the workpiece. The generated heat in the primary deformation zone is transferred into the chip thus the chip carries a great amount of heat during its separation from the workpiece. To investigate the heat generated during chip formation process and consequently the extent of temperature increase (due to the generated heat) from the initial substrate temperature, an elemental atomic volume $\left(1 \times 1.5 \times 3 \mathrm{~nm}^{3}\right.$ including 442 atoms $)$ was considered in the primary deformation zone and the variations of the temperature were monitored on this volume. It can be observed from Fig. 12 that while cutting the (111) plane in the temperature range of $300 \mathrm{~K}$ to $1400 \mathrm{~K}$, the extent of temperature increase caused by the generated heat in the deformation zone is much higher than those of other crystal surfaces, attributable to the release of elastic energy in the 
form of heat during occurrence of cleavage on this crystallographic orientation. However, at 2000 $\mathrm{K}$, the amount of release of heat is smaller than those at lower temperatures due to the weaker bonding between atoms. As stated above, the generated heat in the deformation region is dissipated into the chip thus it is not surprising to see the similar trend for the chip temperature, as depicted in Fig. 13. It must be mentioned here that there may exist some inconsistencies in the observed trends in this study since a multifaceted interplay of various variables such as adhesive forces, interfacial energies, contact areas, number of dangling bonds, nanoscale friction etc. changes with the temperature and crystallographic orientation during nanometric cutting at elevated temperatures.

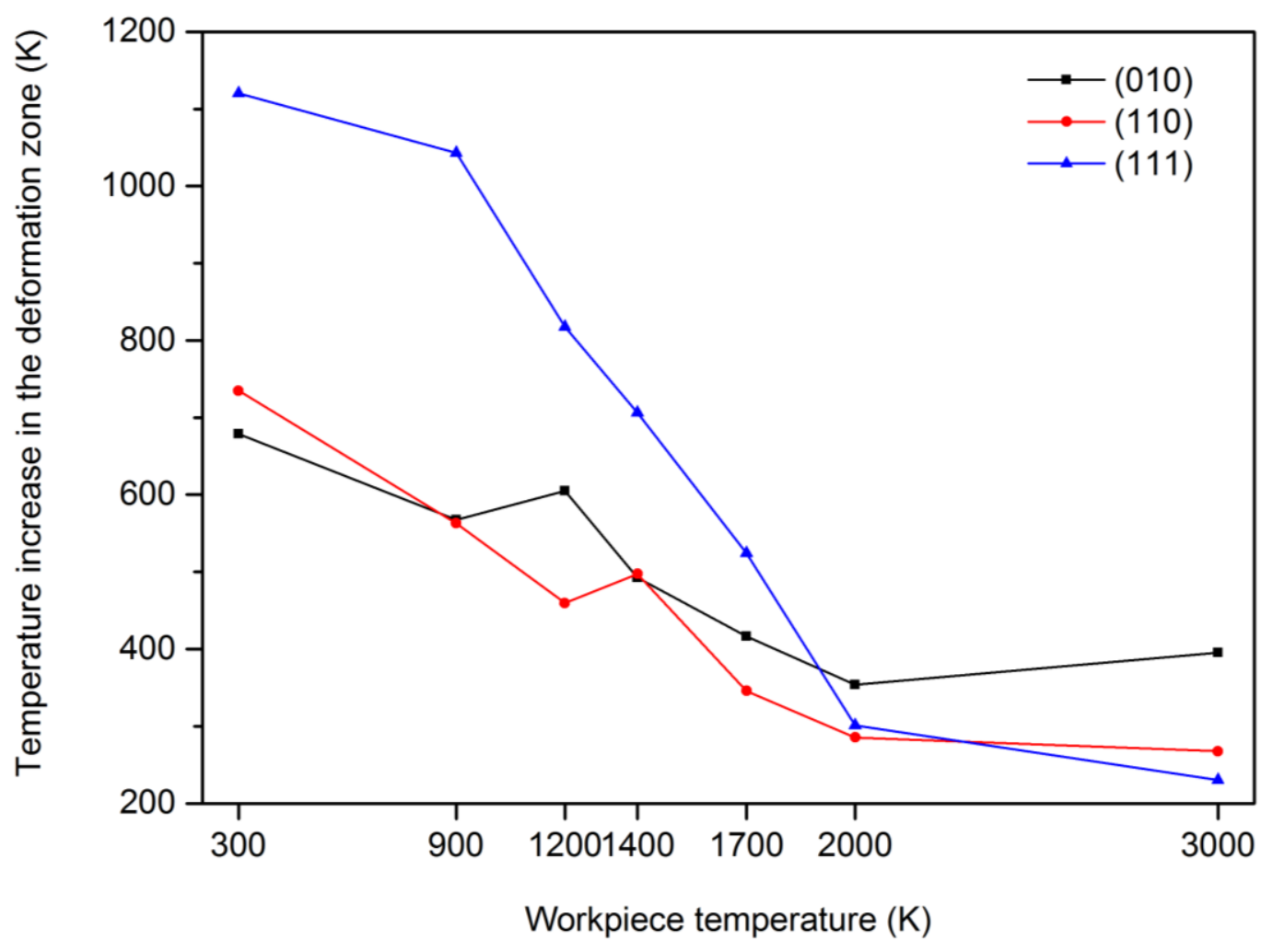

Fig. 12. Extent of temperature increase in the primary deformation zone during chip formation 


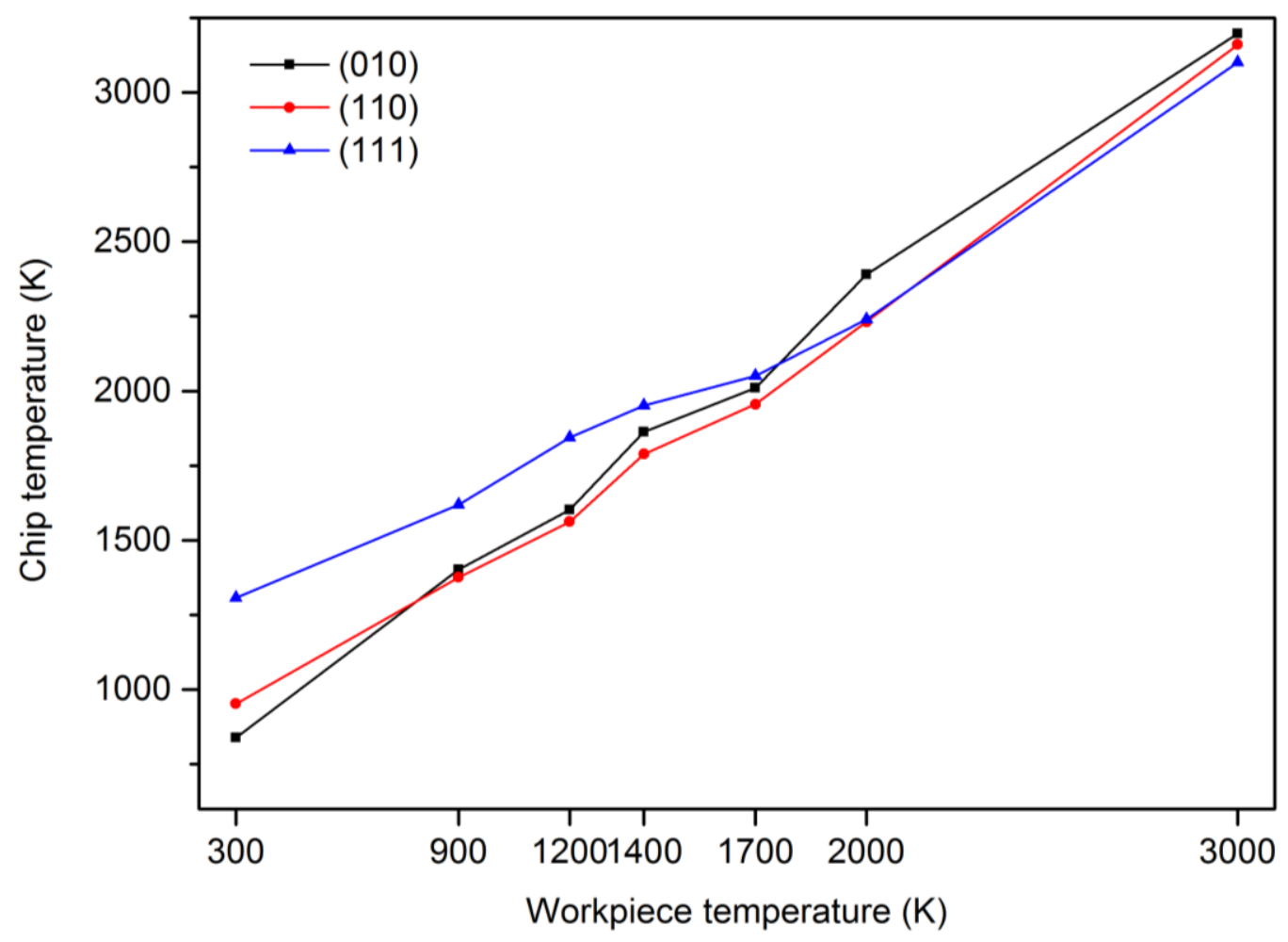

Fig. 13. Chip temperature as a function of cutting temperature and crystal plane

\subsection{Plastic flow behaviour}

In order to investigate the plastic deformation mediated flow behaviour of 3C-SiC during nanometric cutting, the atomic flow field in various zones of the workpiece was determined. Fig. 14 illustrates the displacement vector of atoms after $20 \mathrm{~nm}$ of cutting at $300 \mathrm{~K}$ on the (010), (110) and (111) orientations. A very clear distribution of atomic flow field is apparent in various zones of the workpiece. It can be drawn from Fig. 14 that the atoms beneath the cutting tool in region III experience a rotational flow. This particular flow behaviour of 3C-SiC is analogous to what was observed in our previous study concerning nanometric cutting of silicon [3] and other materials [24]. Nevertheless, there are some discrepancies i.e., in region $I V$, the motion of atoms along the cutting direction is much more marked for the 3C-SiC than silicon workpiece. In particular, with the

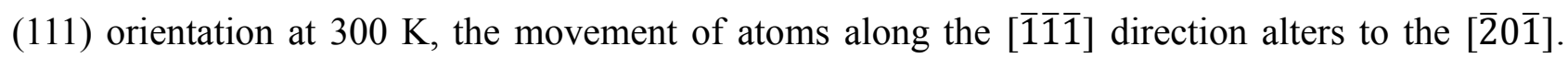
This behaviour can be attributed to the occurrence of cleavage ahead of the cutting tool. Another difference is that the atoms in region $I$ tend to move upwards rather than downwards and backwards 
observed for the silicon. The upwards motion of $3 \mathrm{C}-\mathrm{SiC}$ atoms is more remarkable on the (111) surface plausibly due to the higher elastic recovery, as a consequence of higher ratio of hardness to Young's modulus (H/E), and upper position of stagnation region (see section 3.2), on this crystal orientation as opposed to the other planes. Similar to silicon, the centre of rotational flow underneath the tool while cutting $3 \mathrm{C}$-SiC on the (111) orientation was found to be positioned lower than those of other crystal surfaces, which assists a more effective flow of the atoms within the workpiece. It can, therefore, facilitate the chip formation and material removal during nanometric cutting process. This observation could confirm why the lowest specific cutting energy was realized on the (111) plane.

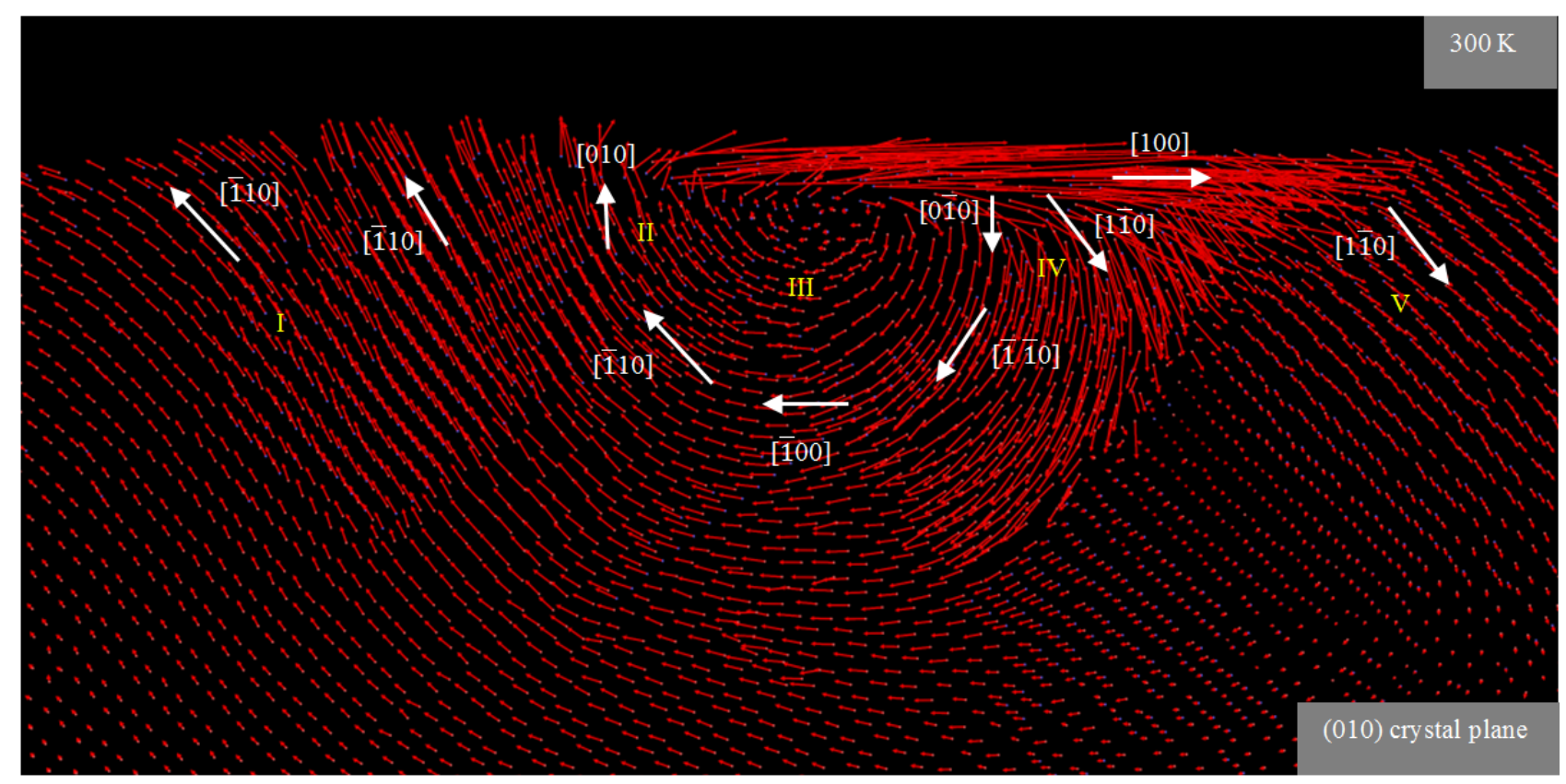



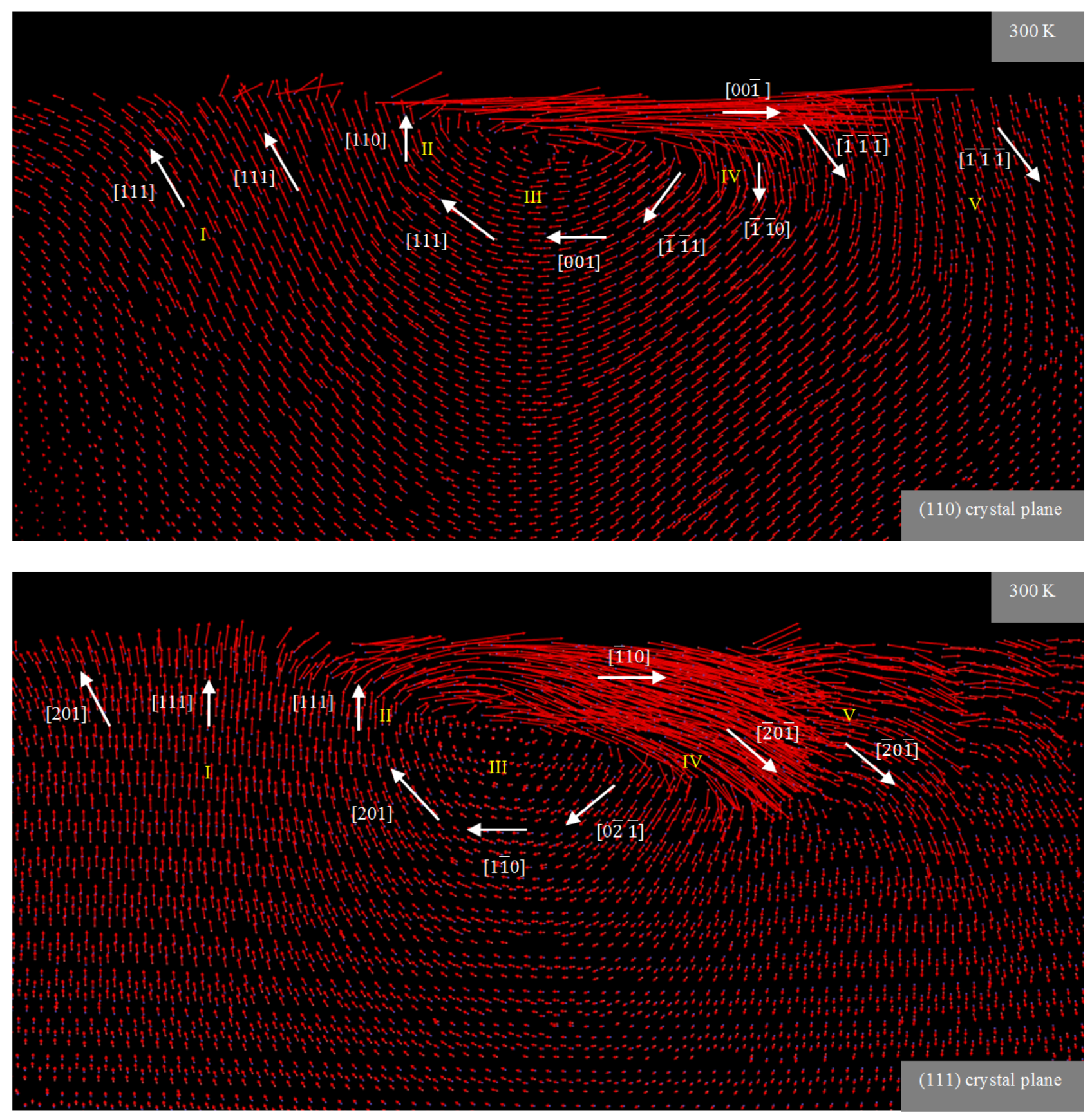

Fig. 14. Atomic flow field in the $X Y$ plane during nanometric cutting of $3 \mathrm{C}$-SiC on the various crystal planes at $300 \mathrm{~K}$. The location of the cutting tool in connection with the different regions can be traced from Fig. 5.

As can be seen from Fig. 15, when nanometric cutting of $3 \mathrm{C}-\mathrm{SiC}$ is carried out at $3000 \mathrm{~K}$, the rotational flow of the atoms in region III is practically eliminated. This fact is more discernible for the (111) crystallographic orientation and atoms show a little turbulence flow. Moreover, as a result of weak van der Waals interactions between atoms at high temperature of $3000 \mathrm{~K}$, the workpiece atoms have tendency to move along the cutting direction. Another notable feature is the existence of 
upward motion of atoms in region $I$ even at high temperature of $3000 \mathrm{~K}$. Accordingly, one would expect to perceive elastic recovery at this temperature. The reason for such observation could be traced at the melting point of $3 \mathrm{C}-\mathrm{SiC}$ predicted by the $\mathrm{ABOP}$ function. A common problem intrinsic to bond order potentials (BOP) for semiconductors is the overestimation of melting point. An attempt was made to calculate the melting point of 3C-SiC predicted by $\mathrm{ABOP}$ using one-phase method and adopting reflective boundaries to diminish the hysteresis phenomenon [25-26]. The phase instability and entirely molten temperature of a $15 \times 15 \times 15$ supercell were observed at $3529 \mathrm{~K}$ and $3993 \mathrm{~K}$, respectively, which are far above the experimental value ( $2800 \mathrm{~K})$. Therefore, satisfactory thermal softening and in turn decline of elastic recovery which ought to be occurred at high temperature of $3000 \mathrm{~K}$ cannot be achieved.

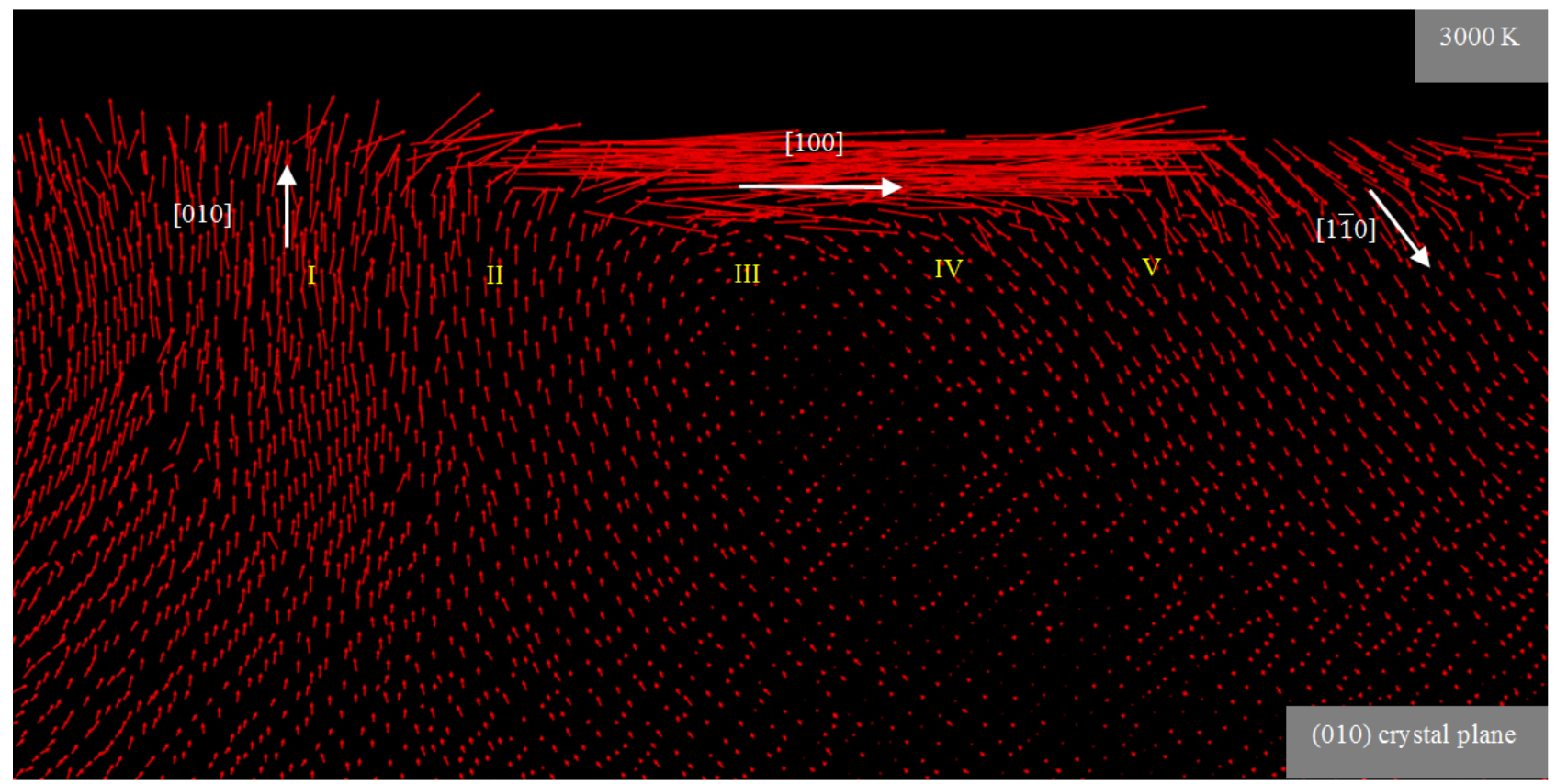



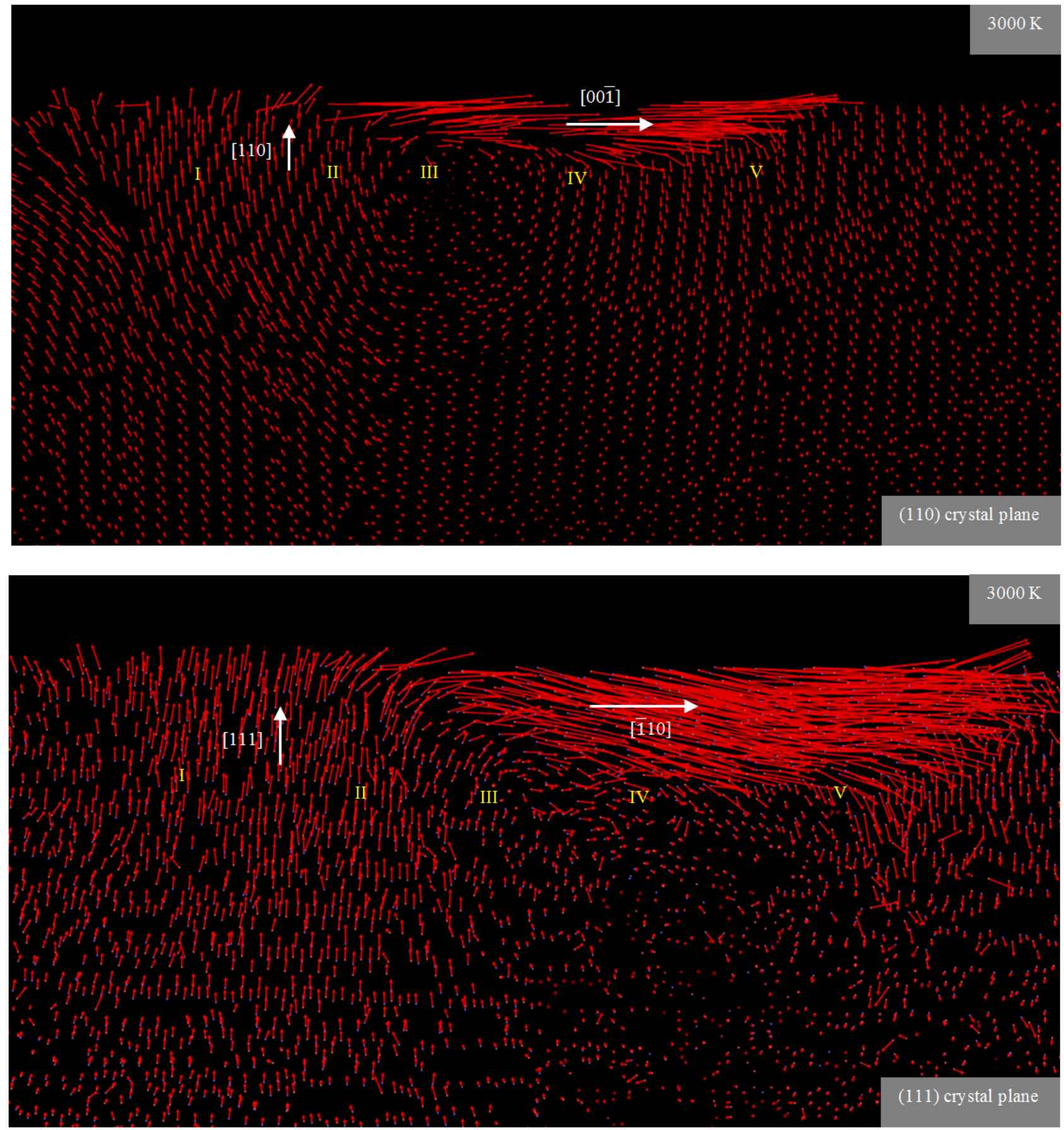

Fig. 15. Atomic flow field during nanometric cutting of $3 \mathrm{C}-\mathrm{SiC}$ on the various crystallographic surfaces at $3000 \mathrm{~K}$

\subsection{Stress, temperature and wear of the cutting edge of the tool}

Figs. 16 and 17 demonstrate the variation of average von Mises stress and temperature measured on the cutting edge of the diamond cutting tool during nanometric cutting of single crystal $3 \mathrm{C}-\mathrm{SiC}$ on different crystallographic orientations at different temperatures. Table 1B in Appendix B lists the 
average magnitude of von Mises stress measure, Tresca stress measure and temperature on the cutting edge in all the simulated test cases.

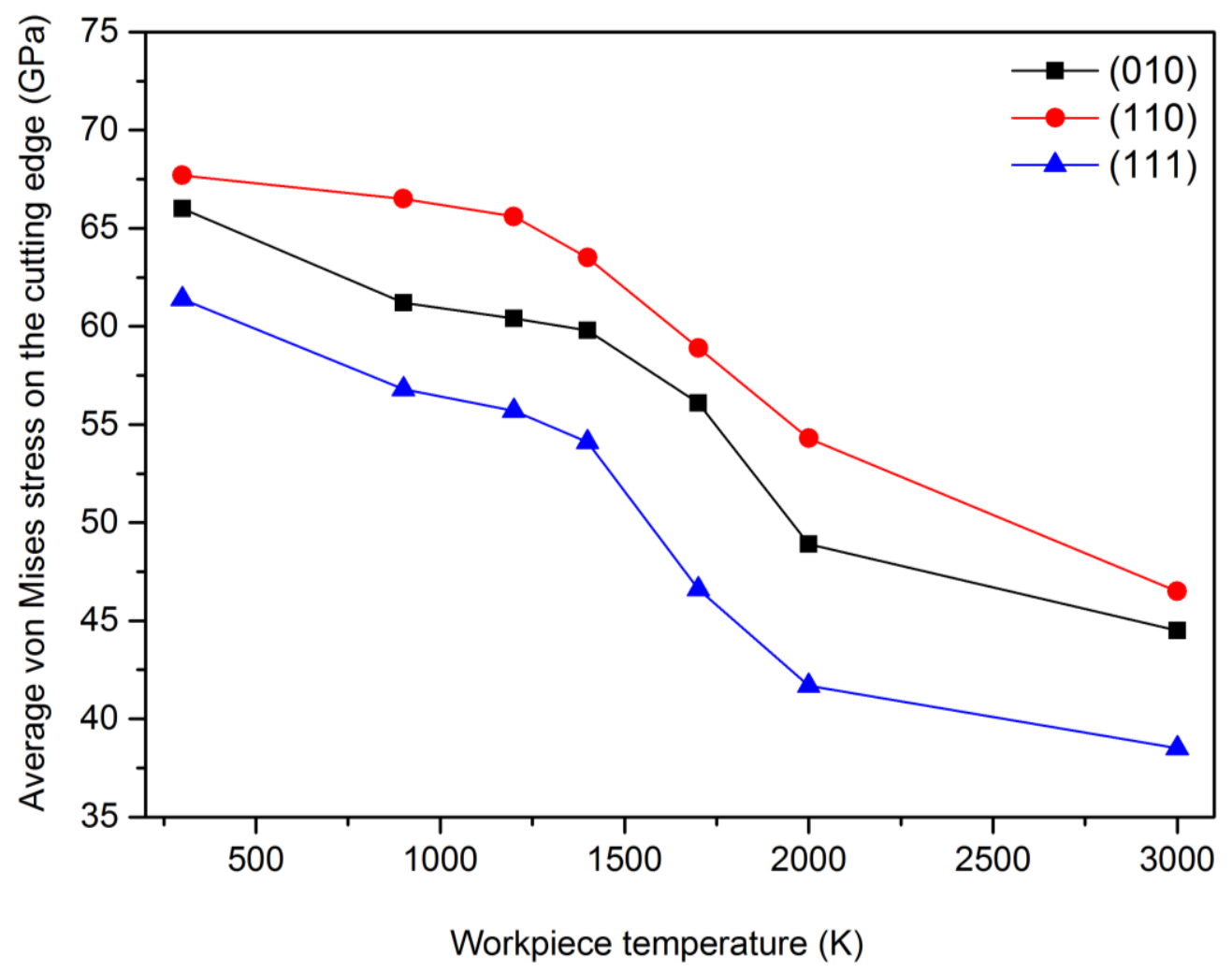

Fig. 16. Variation of the von Mises stress measured on the cutting edge of the diamond tool while cutting different orientations of $3 \mathrm{C}$-SiC at different cutting temperatures 


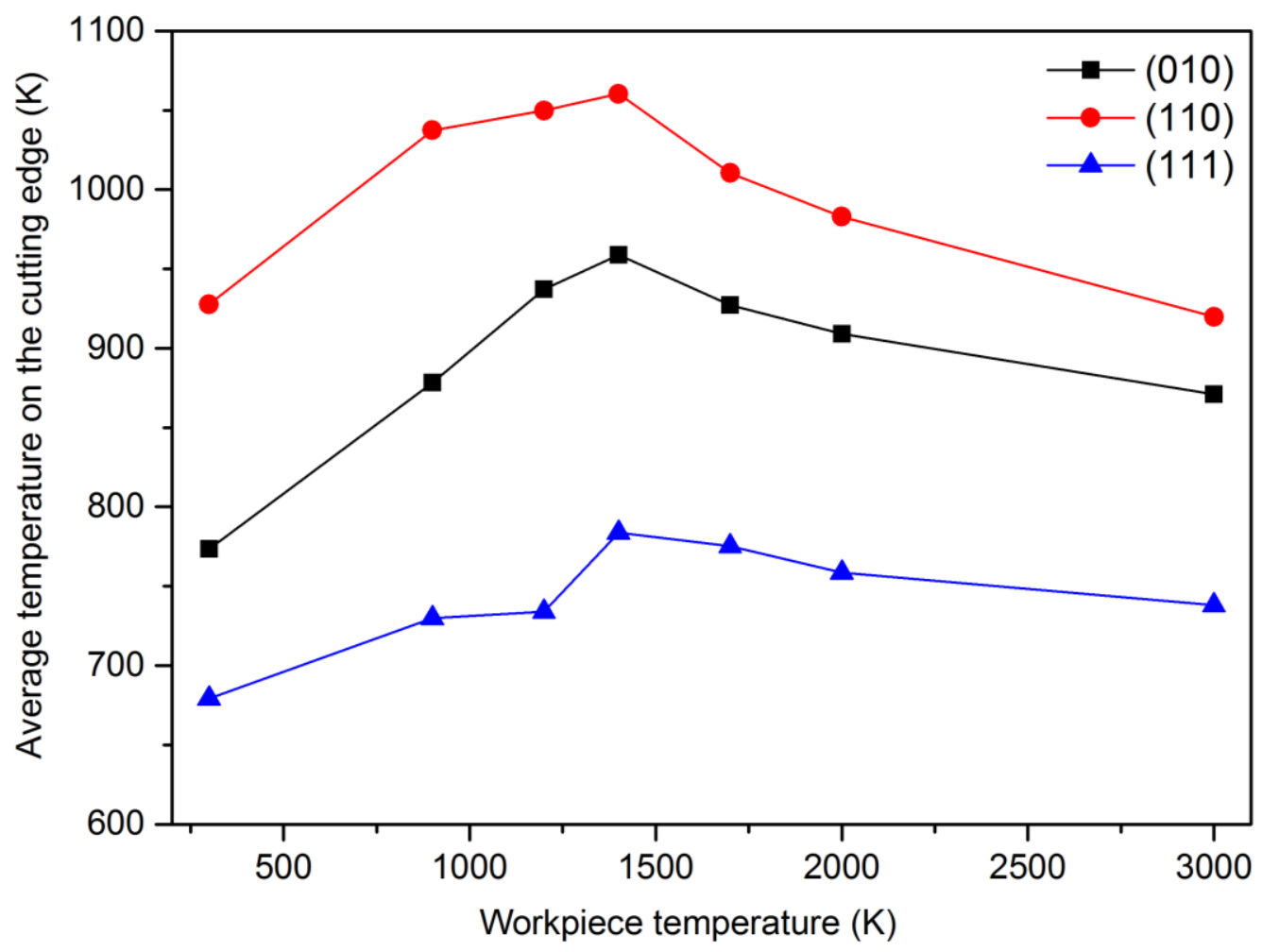

Fig. 17. Variation of temperature measured on the cutting edge of the diamond tool while cutting different orientations of $3 \mathrm{C}$-SiC at different cutting temperatures

It can be observed from Fig. 16 that the cutting tool experiences least stress and temperature on the (111) crystal plane compared to others, which makes it an easy cutting plane, consistent with the observed trend in critical von Mises stress to cause yielding of 3C-SiC during nanometric cutting [22]. Besides, the values of stresses on the cutting edge decrease with the increase of workpiece temperature for the different crystallographic planes. The magnitudes of Mises stress and Tresca stress acting on the cutting edge of the cutting tool at low and high temperatures are found to be in the range of 38 to $68 \mathrm{GPa}$ and 21 to $38 \mathrm{GPa}$, respectively. Clearly, the stress values are lower than $95 \mathrm{GPa}$ [27], which is the minimum stress obtained by first-principle calculation to cause structural instability in the diamond structure. However, as can be seen in Fig. 17, the average temperature on the cutting edge spans from $680 \mathrm{~K}$ to $1060 \mathrm{~K}$ for the different workpiece temperatures and crystallographic orientations. A representative illustration of the temperature distribution on atoms while cutting the (110) crystal plane at $3000 \mathrm{~K}$ is given in Fig. 18. The maximum temperature on the diamond tool is observed on the atoms near the cutting edge. Note that the transient temperature 
at some atoms on the cutting edge might reach $3000 \mathrm{~K}$ but due to high heat conductivity of diamond and usage of thermostatic atoms (to ascertain plausible outward heat conduction away from the machined zone which is carried away by cutting chips and lubricants during actual machining), the average temperature on the cutting edge is in the range of $680 \mathrm{~K}$ to $1060 \mathrm{~K}$.

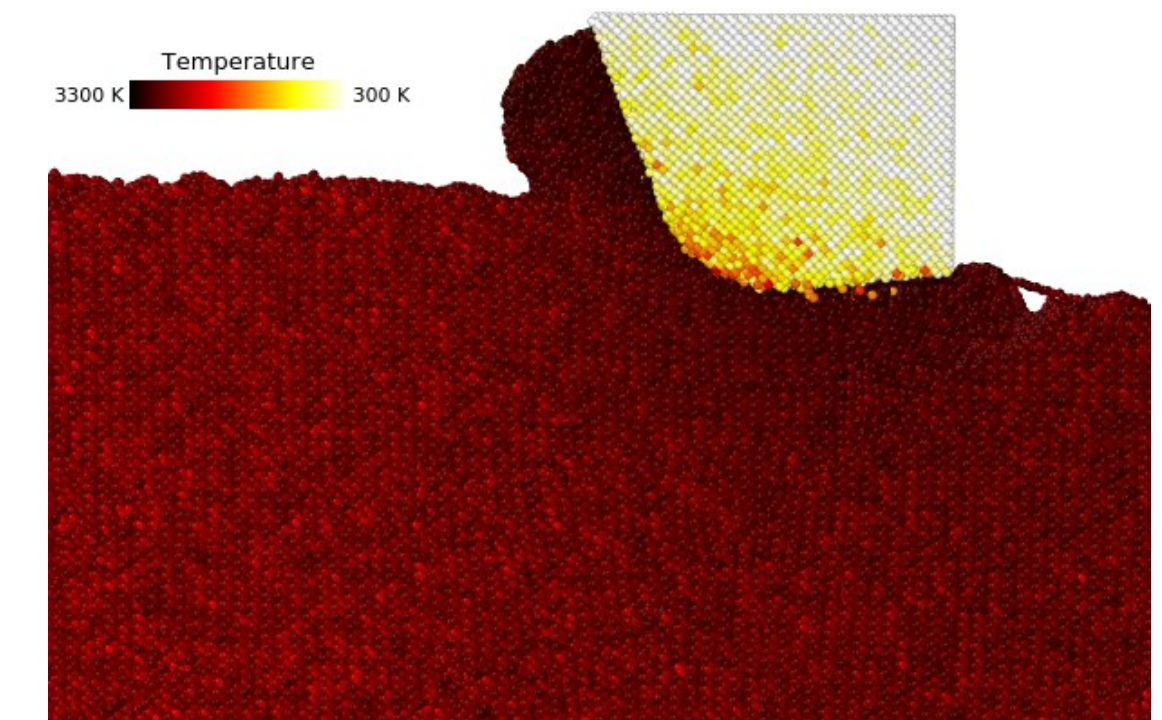

Fig. 18. Temperature distribution on atoms while cutting the (110) crystal plane at $3000 \mathrm{~K}$

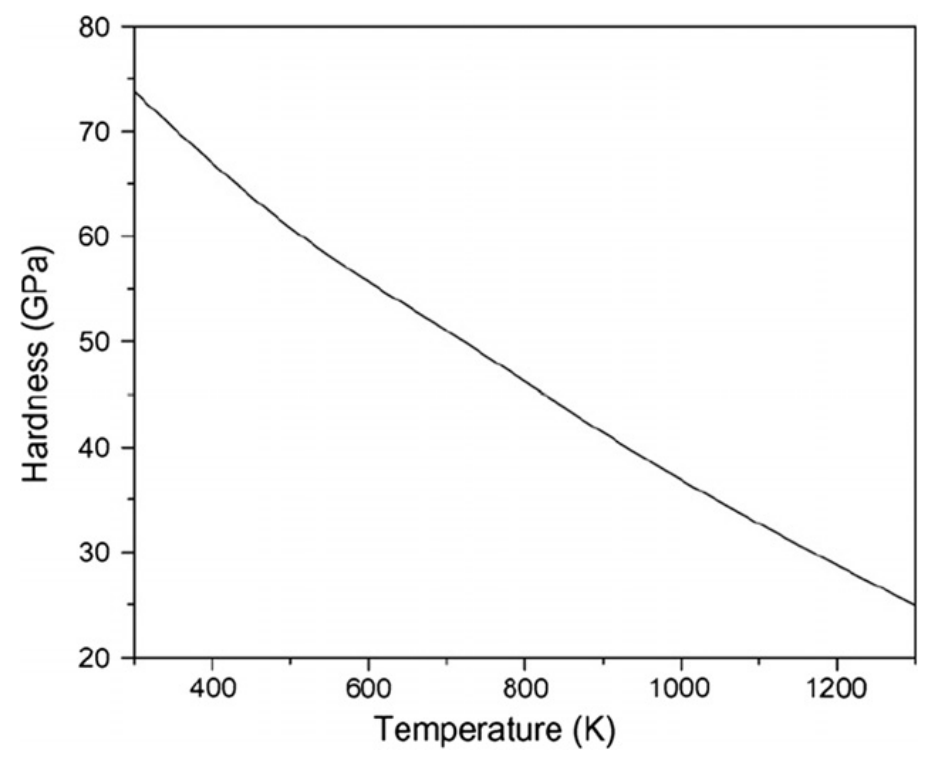

Fig. 19. The hardness of diamond as a function of temperature [28]

As cited by Cai et al. [28], high temperature adversely influences the hardness of diamond i.e. the hardness of diamond drops with the rise of temperature, as illustrated in Fig. 19. It can be observed 
that the hardness of diamond decreases to $\sim 52 \mathrm{GPa}$ and $\sim 33 \mathrm{GPa}$, respectively, at temperatures of $680 \mathrm{~K}$ and $1060 \mathrm{~K}$. On the other hand, at these temperatures i.e. $680 \mathrm{~K}$ and $1060 \mathrm{~K}$, the average von Mises stress acting on the cutting edge is found to be $61.4 \mathrm{GPa}$ while cutting the $(010)$ surface and 63.5 GPa while cutting the (110) plane, respectively. Accordingly, it is not surprising to witness plastic deformation of cutting tool and tool wear via atom-by-atom attrition during nanometric cutting of $3 \mathrm{C}-\mathrm{SiC}$ at different temperatures, as demonstrated in Fig. 20. It is of note that, up to the workpiece temperature of $1400 \mathrm{~K}$, abrasive action between atoms of diamond cutting tool and 3C$\mathrm{SiC}$ workpiece culminates in increasing the temperature on the cutting edge. However, at higher temperatures, due to enhanced thermal softening and decrease of the hardness of workpiece, abrasive action would be mitigated; hence a slight decrease in the temperature on the cutting edge is visible in Fig. 17. Consequently, it can be seen from Fig. 20b that at a workpiece temperature of $2000 \mathrm{~K}$, the atom-by-atom attrition wear is quantitatively less severe than that of $1400 \mathrm{~K}$, which correlates highly with the amount of stresses on the cutting edge at these temperatures. Moreover, the shape of the cutting tool is found to be somewhat deformed while cutting at $1400 \mathrm{~K}$ in comparison with that of $2000 \mathrm{~K}$. These observations confirm that while cutting at high temperatures, the atom-by-atom attrition wear and plastic deformation of the diamond cutting tool could be alleviated. However, chemical wear i.e. dissolution-diffusion and adhesion wear may be accelerated at high temperatures.

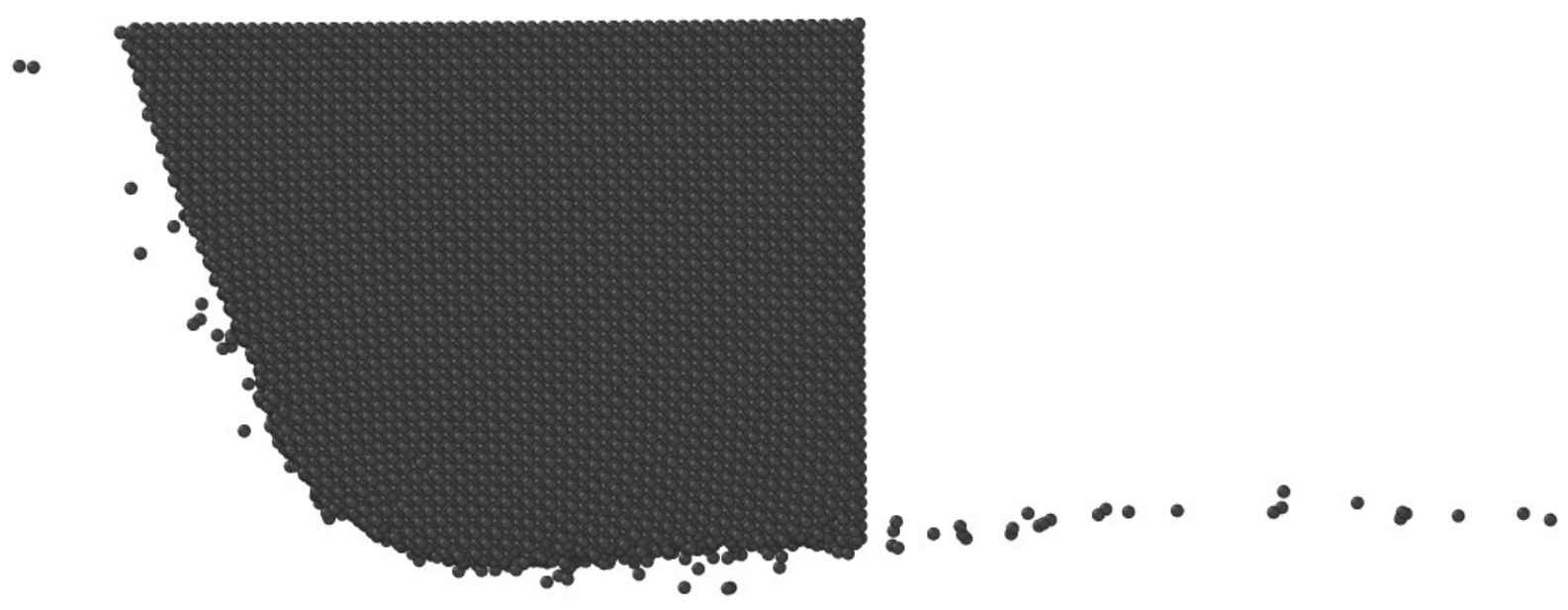


(a)
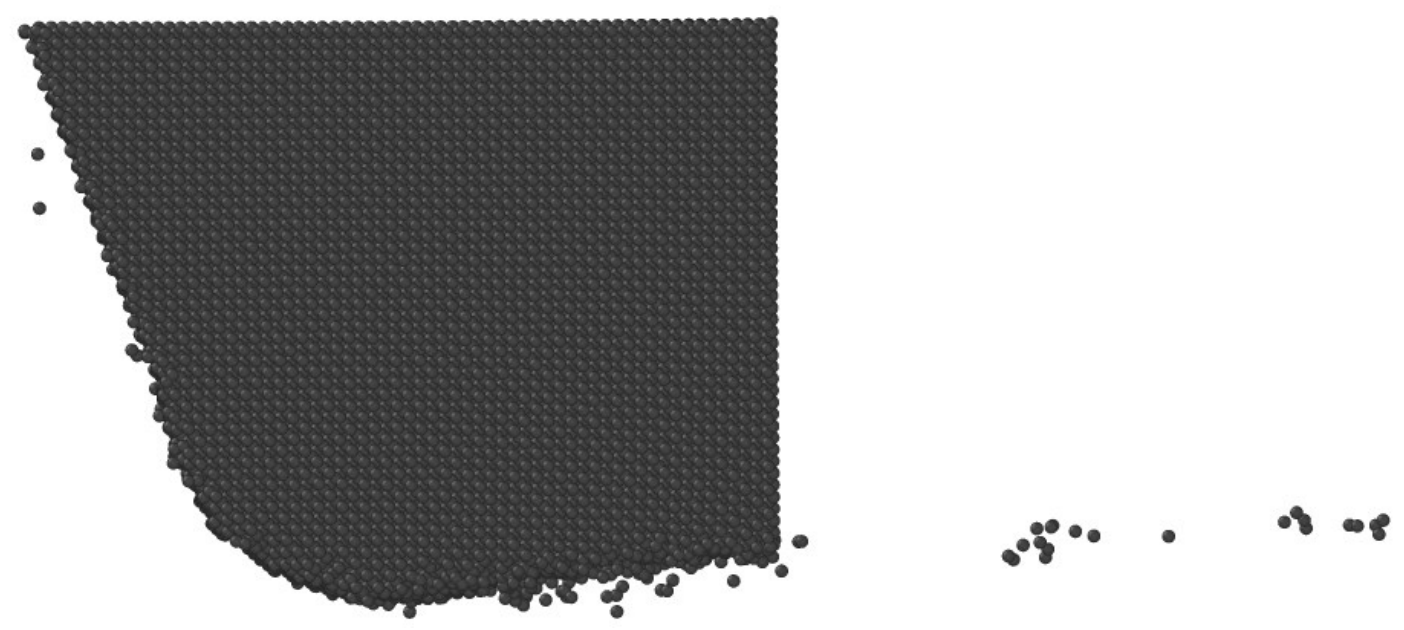

(b)

Fig. 20. Atom-by-atom attrition wear and plastic deformation of diamond cutting tool while nanometric cutting of $3 \mathrm{C}-\mathrm{SiC}$ at a) $1400 \mathrm{~K}$ b) $2000 \mathrm{~K}$

\section{Conclusions}

Due to superior properties of $3 \mathrm{C}-\mathrm{SiC}$, this material has been in the centre of focus as a compound semiconductor to be utilized in the fabrication of devices operating under harsh conditions, leading to a potential demand for cost effective manufacturing of complex 3C-SiC components with mirror finish. Nanometric cutting is now an established ultra-precision manufacturing method to obtain mirror finish and damage-free surfaces with significant cost reduction. However, in nanometric cutting of brittle materials i.e. 3C-SiC, the diamond tool faces tremendous cutting resistance. In such cases, methods are required to be identified to reduce the cutting resistance offered by the substrate so as to improve the machinability. A common understanding about $3 \mathrm{C}-\mathrm{SiC}$ is that high temperature reduces the yield strength and hardness, and improves the fracture toughness which in turn improves its plastic deformation. However, its extent has never been reported as this knowhow could be vital in implementing the hot machining of 3C-SiC with the assistance of Laser processing. This process can open up new horizons for new commercial, technological and scientific developments in the area of manufacturing of $3 \mathrm{C}-\mathrm{SiC}$ space-based laser mirrors, high 
temperature electronics and sensors used in spacecrafts and aircrafts, power devices, microwave electronics used in radar systems, and other applications in the biomedical sector. Taking into account the aforementioned points, MD simulation was employed to investigate the process of nanometric cutting of 3C-SiC on different crystallographic planes i.e. the (010), (110) and (111) under a wide range of workpiece temperatures $(300 \mathrm{~K}-3000 \mathrm{~K})$ in order to shed some light on the mechanisms involved in this process. The primary findings are as follows:

1. The anisotropy in the specific cutting energy initially increased with the increase of cutting temperature up to $1400 \mathrm{~K}$ and then decreased at higher temperatures i.e. $1700 \mathrm{~K}$ and $2000 \mathrm{~K}$.

2. The stagnation region was seen to be positioned at a lower position on the (110) crystal plane or at elevated temperatures. Further analysis revealed that the stagnation and friction angles were closely correlated while cutting the (110) crystal plane in the temperature range of $300 \mathrm{~K}-1400 \mathrm{~K}$.

3. A shift to the (110) cleavage at the cutting temperatures higher than $2000 \mathrm{~K}$ was witnessed. Moreover, crystallites of $3 \mathrm{C}-\mathrm{SiC}$ in the cutting chip was observed in the all simulated temperatures while cutting the (111) plane. Nevertheless, at $3000 \mathrm{~K}$, the amount of cleavage was smaller than those of lower temperatures.

4. The increase of cutting temperature led to the formation of deeper subsurface deformation layer. Maximum damage depth for the preferred cleavage plane of the (111) was found to be consistently larger than those of other planes.

5. The values of resultant force exerted by the tool rake face on the cutting chip were found to be smallest while cutting $3 \mathrm{C}-\mathrm{SiC}$ on the (111) crystal plane whereas they were largest on the (110) surface. Furthermore, the friction coefficient at the tool rake face/chip interface was minimum on the (111) orientation. The friction coefficient at the tool rake face/chip interface on the (111) was observed to constantly decrease with the increase of workpiece temperature. 
6. Much higher extent of temperature increase caused by the generated heat in the deformation region was witnessed while cutting the (111) plane in the cutting temperature range of $300 \mathrm{~K}$ to 1400 , plausibly due to occurrence of cleavage on this crystallographic orientation.

7. Atoms beneath the cutting tool were found to experience a rotational flow, which is practically analogous to the plastic flow behaviour of silicon. The elimination of vortex flow at the cutting temperature of $3000 \mathrm{~K}$ was more manifest for the (111) crystallographic orientation than other surfaces.

8. According to the stress state on the cutting edge of the diamond cutting tool, the atomby-atom attrition wear and plastic deformation of the diamond cutting tool were seen to be alleviated while cutting at high temperatures i.e. $2000 \mathrm{~K}$. However, chemical wear viz. dissolution-diffusion and adhesion wear could be accelerated at high temperatures.

\section{Acknowledgments}

SZC would like to thank the help of Dr. Saurav Goel from Queen's University, Belfast, UK for his useful advice. The authors gratefully acknowledge the financial support from the EPSRC (EP/K018345/1) and Royal Society-NSFC international exchange programme (IE141422) for this study. The authors also acknowledge the use of the EPSRC (EP/K000586/1) funded ARCHIE-WeSt High Performance Computer at the University of Strathclyde.

\section{Appendix A}

Table 1A. Average forces and specific cutting energy while cutting single crystal 3C-SiC on different crystallographic orientations at various temperatures

\begin{tabular}{|c|c|c|c|c|c|}
\hline Workpiece & Crystal & Average & Average & Average & Average \\
temperature & orientation & tangential & thrust & resultant & specific \\
\hline
\end{tabular}




\begin{tabular}{|c|c|c|c|c|c|}
\hline$(\mathrm{K})$ & & $\begin{array}{c}\text { cutting } \\
\text { force }(\mathrm{nN})\end{array}$ & $\begin{array}{l}\text { force } \\
(\mathrm{nN})\end{array}$ & $\begin{array}{l}\text { force } \\
(\mathrm{nN})\end{array}$ & $\begin{array}{l}\text { cutting } \\
\text { energy } \\
(\mathrm{GPa})\end{array}$ \\
\hline \multirow{3}{*}{300} & $(010)$ & 2112 & 4564.8 & 5029.7 & 381 \\
\hline & $(110)$ & 2280.5 & 4660.6 & 5188.6 & 393.1 \\
\hline & $(111)$ & 2122.3 & 2943.1 & 3628.5 & 274.9 \\
\hline \multirow{3}{*}{900} & $(010)$ & 1863.7 & 4156.8 & 4555.5 & 345.1 \\
\hline & $(110)$ & 1988 & 4462.9 & 4885.7 & 370.1 \\
\hline & $(111)$ & 1781 & 2393.4 & 2983.4 & 226 \\
\hline \multirow{3}{*}{1200} & $(010)$ & 1869.7 & 4100.4 & 4506.6 & 341.4 \\
\hline & $(110)$ & 1888.5 & 4463.5 & 4846.6 & 367.2 \\
\hline & $(111)$ & 1741.6 & 2270.7 & 2861.7 & 216.8 \\
\hline \multirow{3}{*}{1400} & $(010)$ & 1792.9 & 3691.4 & 4103.8 & 310.9 \\
\hline & $(110)$ & 1934.8 & 4349.3 & 4760.2 & 360.6 \\
\hline & $(111)$ & 1680.3 & 2062.3 & 2660.1 & 201.5 \\
\hline \multirow{3}{*}{1700} & $(010)$ & 1604.7 & 2983.1 & 3387.3 & 256.6 \\
\hline & (110) & 1841.1 & 3459.6 & 3919 & 296.9 \\
\hline & (111) & 1554.9 & 1947.8 & 2492.3 & 188.8 \\
\hline \multirow{3}{*}{2000} & $(010)$ & 1433.6 & 2526.2 & 2904.7 & 220 \\
\hline & $(110)$ & 1672.7 & 2804.8 & 3265.7 & 247.4 \\
\hline & (111) & 1606.3 & 1864.1 & 2460.7 & 186.4 \\
\hline \multirow{3}{*}{3000} & $(010)$ & 1067.1 & 1717 & 2021.6 & 153.1 \\
\hline & (110) & 1330.6 & 2039.5 & 2435.2 & 184.5 \\
\hline & $(111)$ & 1267.6 & 1402.9 & 1890.8 & 143.2 \\
\hline
\end{tabular}


Table 1B. Average stresses and temperature on the cutting edge of the diamond tool while cutting single crystal 3C-SiC on different crystallographic orientations at various temperatures

\begin{tabular}{|c|c|c|c|c|}
\hline $\begin{array}{c}\text { Workpiece } \\
\text { temperature } \\
\text { (K) }\end{array}$ & $\begin{array}{c}\text { Crystal } \\
\text { orientation }\end{array}$ & $\begin{array}{l}\text { von Mises } \\
\text { stress on the } \\
\text { cutting edge } \\
\text { (GPa) }\end{array}$ & $\begin{array}{l}\text { Tresca stress } \\
\text { on the } \\
\text { cutting edge } \\
\text { (GPa) }\end{array}$ & $\begin{array}{c}\text { Temperature } \\
\text { on the } \\
\text { cutting edge } \\
\text { (K) }\end{array}$ \\
\hline \multirow{3}{*}{300} & $(010)$ & 66 & 38 & 773.6 \\
\hline & (110) & 67.7 & 38.3 & 927.8 \\
\hline & (111) & 61.4 & 34.3 & 679.1 \\
\hline \multirow{3}{*}{900} & $(010)$ & 61.2 & 34.3 & 878.5 \\
\hline & (110) & 66.5 & 38 & 1037.3 \\
\hline & (111) & 56.8 & 32.6 & 729.9 \\
\hline \multirow{3}{*}{1200} & $(010)$ & 60.4 & 34.1 & 937.2 \\
\hline & $(110)$ & 65.6 & 37 & 1049.8 \\
\hline & (111) & 55.7 & 32.9 & 733.9 \\
\hline \multirow{4}{*}{1400} & $(010)$ & 59.8 & 33.7 & 958.9 \\
\hline & $(110)$ & 63.5 & 36.3 & 1060.3 \\
\hline & (111) & 54.1 & 31.3 & 783.8 \\
\hline & $(010)$ & 56.1 & 32.2 & 927.3 \\
\hline
\end{tabular}




\begin{tabular}{|c|c|c|c|c|}
\hline 1700 & $(110)$ & 58.9 & 35.3 & 1010.4 \\
\cline { 2 - 5 } & $(111)$ & 46.6 & 28.9 & 775.3 \\
\hline \multirow{3}{*}{2000} & $(010)$ & 48.9 & 27.1 & 909.5 \\
\cline { 2 - 5 } & $(110)$ & 54.3 & 30.1 & 983 \\
\cline { 2 - 5 } & $(111)$ & 41.7 & 22.6 & 758.6 \\
\hline \multirow{3}{*}{3000} & $(010)$ & 44.5 & 24.7 & 871.4 \\
\cline { 2 - 5 } & $(110)$ & 46.5 & 25.2 & 919.8 \\
& $(111)$ & 38.5 & 21.1 & 738.2 \\
\cline { 2 - 5 } & & & & \\
\hline
\end{tabular}

\section{References}

[1] P. Mélinon, B. Masenelli, F. Tournus, A. Perez, Playing with carbon and silicon at the nanoscale. Nature Materials 6 (2007) 479-490

[2] S. Goel, W.B. Rashid, X. Luo, A. Agrawal, V. K. Jain, A theoretical assessment of surface defect machining and hot machining of nanocrystalline silicon carbide. Journal of Manufacturing Science and Engineering, 136 (2) (2014) 021015

[3] S. Z. Chavoshi, S. Goel, X. Luo, Molecular dynamics simulation investigation on plastic flow behaviour of silicon during nanometric cutting. Modelling Simul. Mater. Sci. Eng. 24 (2016) 015002

[4] S. Z. Chavoshi, X. Luo, An atomistic simulation investigation on chip related phenomena in nanometric cutting of single crystal silicon at elevated temperatures. Computational Materials Science, 113, (2016) 1-10 
[5] S. Z. Chavoshi, S. Xu, X. Luo, Dislocation-mediated plasticity in silicon during nanometric cutting: A molecular dynamics simulation study, Materials Science in Semiconductor Processing, $51,(2016) 60-70$

[6] S. Z. Chavoshi, S. Goel, X. Luo, Influence of temperature on the anisotropic cutting behaviour of single crystal silicon: A molecular dynamics simulation investigation. Journal of Manufacturing Processes, Accepted

[7] T-H Fang, C-I Weng, J-G Chang, Molecular dynamics analysis of temperature effects on nanoindentation measurement. Materials Science and Engineering A, 357 (2003) 7-12

[8] C-L Liu, T-H Fang, J-F Lin, Atomistic simulations of hard and soft films under nanoindentation. Materials Science and Engineering A 452-453 (2007) 135-141

[9] J-Y Hsieh, S-P Ju, S-H Li, C-C Hwang, Temperature dependence in nanoindentation of a metal substrate by a diamond-like tip. Physical Review B (2004) 70, 195424

[10] H. Zhao, P. Zhang, C. Shi, C. Liu, L. Han, H. Cheng, L. Ren, Molecular dynamics simulation of the crystal orientation and temperature influences in the hardness on monocrystalline silicon. Journal of Nanomaterials, (2014) Article ID 365642

[11] P. Erhart, K. Albe, Analytical potential for atomistic simulations of silicon, carbon, and silicon carbide. Physical Review B, 71(3) (2005) 035211

[12] S. Plimpton, Fast parallel algorithms for short-range molecular-dynamics. Journal of computational physics, 117 (1) (1995) 1-19

[13] J. Belak, Nanotribology: modelling atoms when surfaces collide Energ. Tech. Rev. (1994), pp. $13-24$ 
[14] N. Chandrasekaran, A. Noori Khajavi , L. M. Raff, R. Komanduri, A new method for molecular dynamics simulation of nanometric cutting. Philosophical Magazine Part B, 77:1, 7-26 (1998)

[15] R. Komanduri, N. Chandrasekaran, and L. M. Raff, Molecular dynamics simulation of atomicscale friction. Phys. Rev. B 61, 14007 (2000)

[16] R. Komanduri , N. Ch and rasekaran \& L. M. Raff (2001) Molecular dynamics simulation of the nanometric cutting of silicon, Philosophical Magazine Part B, 81:12, 1989-2019.

[17] R. Komanduri, N. Chandrasekaran \& L. M. Raff (1999) Some aspects of machining with negative-rake tools simulating grinding: A molecular dynamics simulation approach, Philosophical Magazine Part B, 79:7, 955-968

[18] Z. Li, R. C. Bradt, Thermal expansion of the cubic (3C) polytype of SiC. Journal of Materials Science 21 (1986) 4366-4368

[19] A. Stukowski, Visualization and analysis of atomistic simulation data with OVITO-the Open Visualization Tool. Modelling Simul. Mater. Sci. Eng. 18 (2010), 015012

[20] S. Goel, A. Stukowski, X. Luo, A. Agrawal, R. L. Reuben, Anisotropy of single-crystal 3C-SiC during nanometric cutting. Modelling Simul. Mater. Sci. Eng. 21 (2013) 065004

[21] J. E. Field, The mechanical and strength properties of diamond. Rep. Prog. Phys. 75 (2012) 126505

[22] S. Z. Chavoshi, X. Luo, Molecular dynamics simulation study of deformation mechanisms in 3C-SiC during nanometric cutting at elevated temperatures. Materials Science and Engineering: A, 654 (2016) 400-417

[23] C. A. Brookes, E. J. Brookes, V. R. Howes, S. G. Roberts, and C. P. Waddington, A comparison of the plastic deformation and creep of type I, type II and synthetic diamonds at $1100^{\circ} \mathrm{C}$ under conditions of point loading. J. Hard Mater, 1 (1) 1990 
[24] G.L. Cross, B.S. O'Connell, H.O. Özer, J.B. Pethica. Room temperature mechanical thinning and imprinting of solid films, Nano Lett 7 (2007) 357-362

[25] H. T.T. Nguyen, V. V. Hoang, L. N. T. Minh, Melting of crystalline silicon thin films. Computational Materials Science 89 (2014) 97-101

[26] Q. Zhang, Q. Li, M. Li, Melting and superheating in solids with volume shrinkage at melting: A molecular dynamics study of silicon. The journal of chemical physics 138 (2013) 044504

[27] H. Chacham, L. Kleinman, Instabilities in diamond under high shear stress. Physical Review Letters 85(23) (2000) 4904-4907

[28] M. B. Cai, X. P. Li, M. Rahman, Study of the temperature and stress in nanoscale ductile mode cutting of silicon using molecular dynamics simulation. Journal of Materials Processing Technology 192- 193 (2007) 607-612 